ISSN 2414-987X
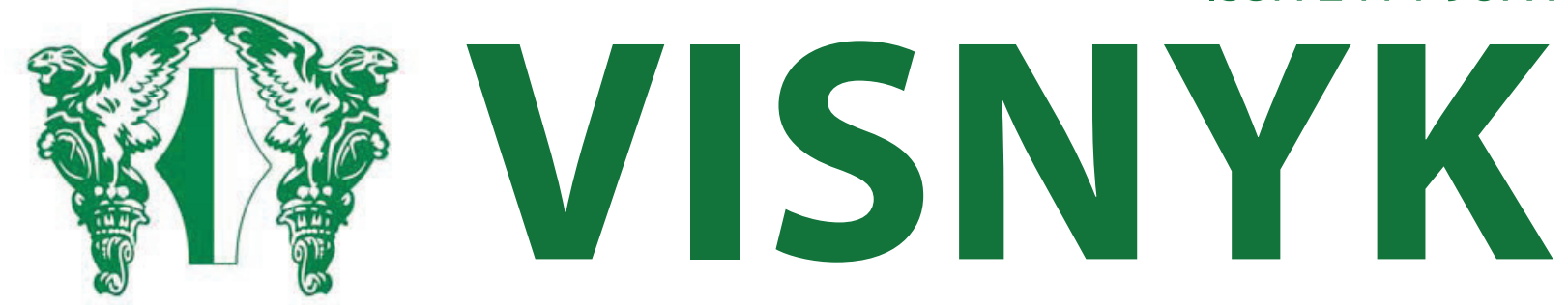

OF THE NATIONAL BANK OF UKRAINE

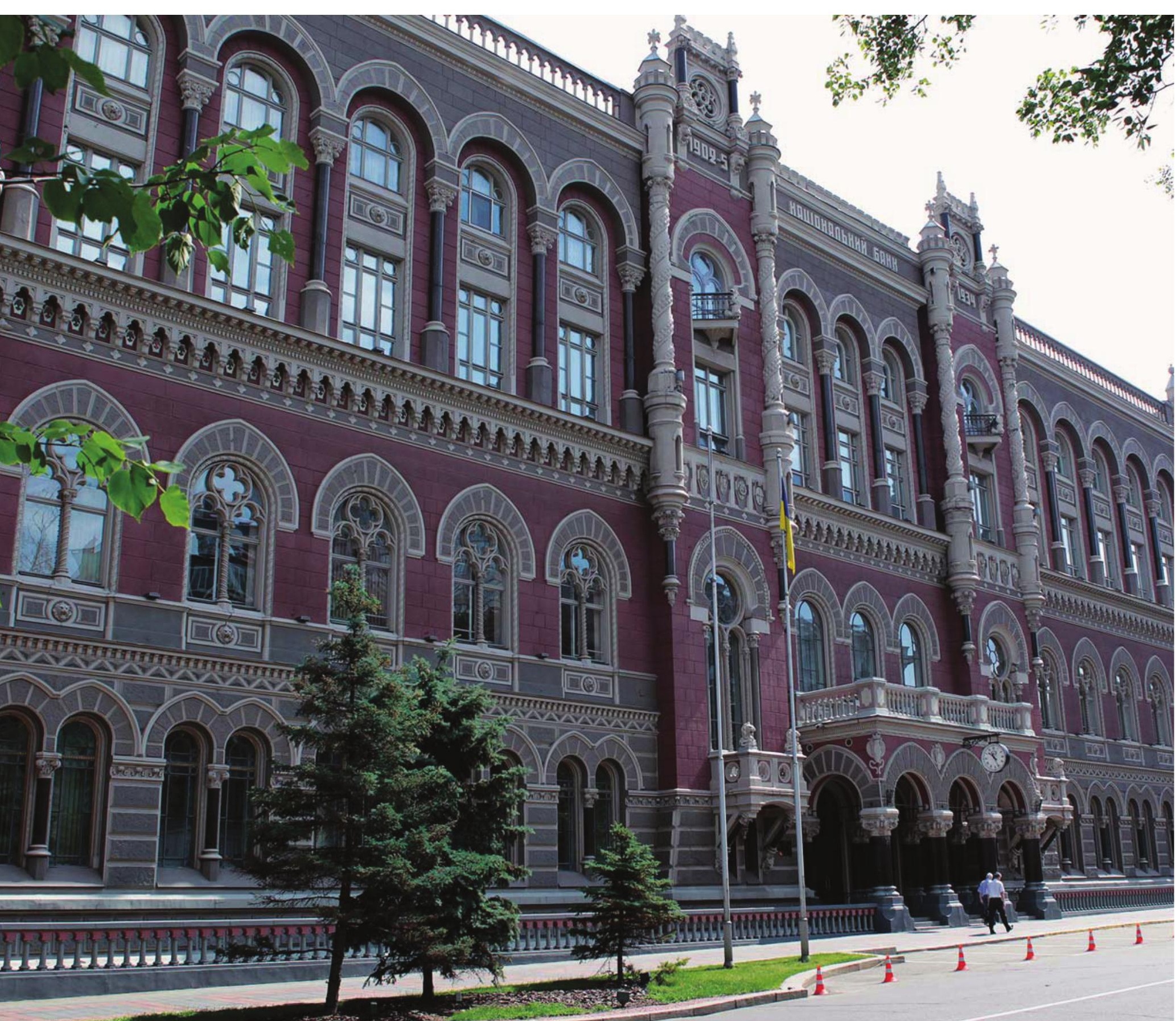

QUARTERLYRESEARCH

JOURNAL OF THE NATIONAL BANK OF UKRAINE 


\section{№ 236}

Quarterly research Journal of the National Bank of Ukraine

Published since March 1995

\section{Editorial Board}

\section{Dmytro Sologub}

Chairman of the Editorial

Board,

Deputy Governor,

the National Bank of Ukraine

\section{Vladyslav Rashkovan}

Deputy Governor, the National

Bank of Ukraine

\section{Vitaliy Vavryshchuk}

Director of Financial Stability

Department, the National Bank of Ukraine

\section{Yuriy Gorodnichenko}

Associate Professor, University of

California, Berkeley, PhD

\section{Oleksandr Petryk}

Alternative Executive Director, the International Monetary Fund, $\mathrm{PhD}$

\section{Sergiy Nikolaychuk}

Deputy Chairman,

Director of Monetary Policy

and Economic

Analysis Department, the National Bank

of Ukraine, $\mathrm{PhD}$

\section{Oleksiy Kryvtsov}

Director in the International

Economic Analysis Department,

Bank of Canada, PhD

\section{Tom Coupe}

Associate Professor, Senior Economist, the Kyiv School of Economics, PhD
(C) National Bank of Ukraine 1995-2016

All rights reserved

https://doi.org/10.26531/vnbu2016.236

Address: 9 Instytutska Street, Kyiv, 01601, Ukraine Email: journal@bank.gov.ua

Design and layout:

"INPRESS" LLC.

Address: 46 Zolotoustivska st., Apt. 7, Kyiv, 01135, Ukraine.

Tel.: +380 (44) 234-78-68.

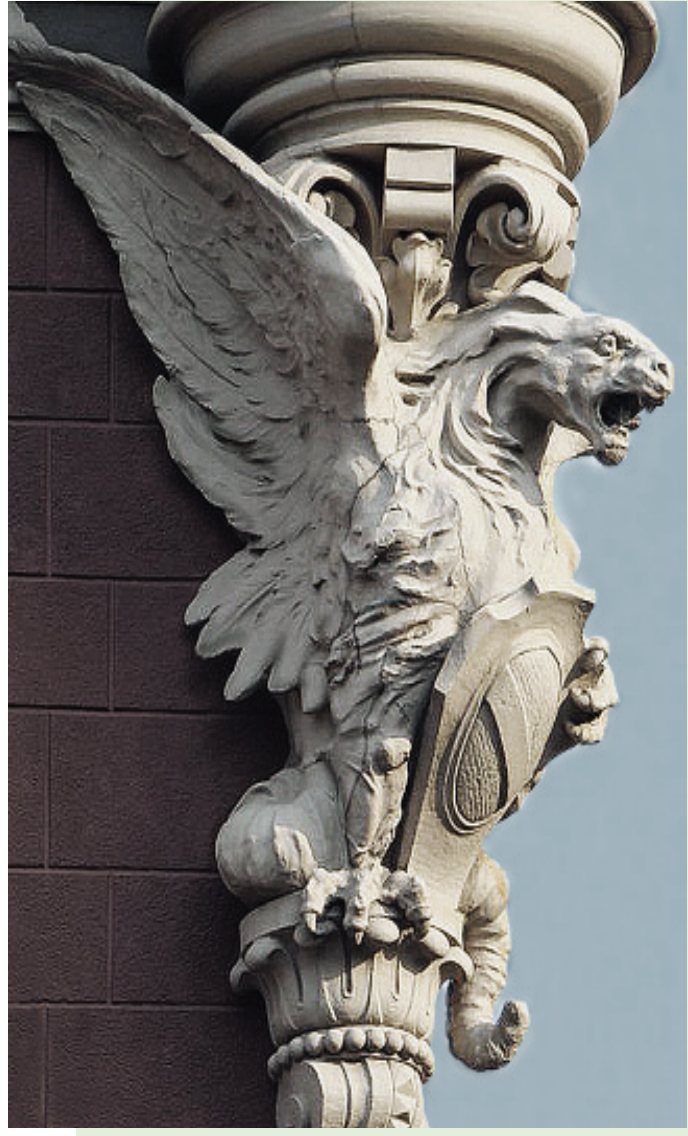

Founder and publisher:

National Bank of Ukraine

Editorial board ensures compliance with ethical standards of publishing

For reprinting materials published herein the reference to the journal "Visnyk of the National Bank of Ukraine" is compulsory

The Editorial Board can publish materials being under discussion, not sharing the author's opinion

The author bears responsibility for the accuracy of the materials 


\section{PREFACE OF THE CHAIRMAN OF THE EDITORIAL BOARD}

\section{Dear readers,}

The Annual Research Conference of the National Bank of Ukraine Transformation of Central Banking, organized in cooperation with Narodowy Bank Polski and with the support of the Government of Canada and the Kyiv School of Economics, took place in Kyiv on 19-20 May 2016. More than 300 participants took part in the event, among them central bankers, representatives of international financial organizations, and Ukrainian and foreign scholars and experts. The Conference became the next step in the purposeful and consistent work of the National Bank of Ukraine for integration into the international research community. Development of this function is an integral part of central banking in most countries of the world because applied and fundamental studies are necessary prerequisites for preparing and making high quality policy decisions by central banks.

A review article Transformation of Central Banking. Annual Research Conference of the NBU. Key Issues on the outcomes and conclusions from the Conference speeches opens this issue. The material is structured chronologically in accordance with the key speeches, research sessions, and panel discussions. Analyzing the rapid macroeconomic changes in many countries and transformations within the global financial market, the participants emphasized that these factors considerably alter the nature of the global banking system. Under the circumstances, central banks are systemically transforming their functions. Central banks, faced with a wide range of problems, are forced to look for new ideas and developments based on analytical data and international best practices with new instruments to solve urgent problems. In order to reach their main goals (price and financial stability, sustainable economic growth), central banks now use a range of unconventional monetary instruments, work on improvement of the monetary transmission mechanism and macroprudential supervision, apply a new approach to capital flows management, implement innovative models into payment operations, etc. The article focuses on the key conclusions from the speeches and discussions of their outcomes, as well as on recommendations to use in current and future central banking.

The following article in the issue is Institutional Set-up and Mandates of Macroprudential Authorities: International Experience and Benchmarks for Ukraine by Andriy Danylenko and Viktoriia Sanzharovska. It elaborates on the development of a macroprudential architechture as the key element for ensuring financial stability. General principles defined by international organizations allow for different ways to implement macroprudential supervision suitable for the level of development of each country's financial system, as well as to take into consideration the division of responsibilities in the area between the government and the central bank. In most countries, the central bank has a mandate for macroprudential supervision, especially if it is also responsible for supervision 
and regulation of the financial sector. Based on an analysis of the bank-dominated financial system in Ukraine and international best practices, the authors come to a conclusion regarding the advisability to entrust a macroprudential supervision mandate to the National Bank of Ukraine.

Oleksandr Faryna's article Nonlinear Exchange Rate Pass-Through to Domestic Prices in Ukraine aims at estimating the asymmetric impact of the nominal effective exchange rate on consumer prices in Ukraine taking into account the size and direction of exchange rate movements. The author concludes that the pass-through effect on core inflation is considerably higher as a result of the national currency's depreciation than in the case of its appreciation, which attests to the high level of market monopolization. Also, the research results suggest that consumer price responsiveness to small, medium, and large exchange rate changes is nonlinear. While the pass-through effect on consumer prices of small and large exchange rate movements is considerable, the effect of moderate exchange rate movements is insignificant. The article provides yet another justification for the NBU to apply an inflation targeting regime for which moderate exchange rate movements are characteristic. At the same time, the article explains why in the past, under conditions of a strict exchange rate peg and regular foreign exchange crises, consumer inflation was so anchored to the exchange rate movements.

We hope that the materials in this issue will be of use to a wide range of experts and scholars of macroeconomic and monetary development, banking and other areas. The editorial board invites all those willing to participate in new research to send us original articles with well-grounded conclusions and recommendations for further consideration and publishing in the Visnyk of the National Bank of Ukraine. 


\section{CONTENTS}

Sergiy Nikolaychuk, Roman Pidvysotskyi

Transformation of Central Banking. Annual Research Conference of the NBU.

Key Issues $\quad 6$

Andriy Danylenko, Viktoriia Sanzharovska

Institutional Set-Up and Mandates of Macroprudential Authorities:

International Experience and Benchmarks for Ukraine

Oleksandr Faryna

Nonlinear Exchange Rate Pass-Through to Domestic Prices in Ukraine 


\title{
Transformation of Central Banking. Annual Research Conference of the NBU. Key Issues
}

\section{Sergiy Nikolaychuk}

National Bank of Ukraine

\author{
Roman Pidvysotskyi \\ National Bank of Ukraine
}

\begin{abstract}
In May 2016, the National Bank of Ukraine (NBU) held its Annual Research Conference on Transformation of Central Banking for the first time. Over 300 participants shared in the work of the representative international forum, including experts from central banks and international financial organizations, as well as representatives of the Ukrainian and international academic community. Issues discussed during the conference included the recent trends in central banking, ranging from the monetary policy at low interest rates and under the threat of deflation, financial stability and management of capital flows, and the effect of new financial technologies and cultural features on the transition process in central banks.
\end{abstract}

The global financial system has changed rapidly and constantly during recent decades. Therefore, central banks must also transform quickly and efficiently to be in line with economic processes and financial markets, which likewise develop rapidly and become more complex.

The great recession made it clear that the traditional set of central banks' instruments proved insufficient to restore sustainable economic growth and financial stability. Accordingly, central banks began actively implementing new approaches and regulatory measures over the past 10 years.

In particular, central banks in developed countries tend to use innovative instruments to counter deflationary pressure. Meanwhile, those central banks considered as models for implementing monetary policy in the context of inflation targeting (IT) returned to the practice of using special techniques for exchange rate management, which in the past were considered incompatible with this monetary regime. For example, the Czech National Bank is actively implementing the practice of maintaining the upper level of the exchange rate, while the central bank of Sweden (Sveriges Riksbank) considers the possibility of conducting FX interventions in addition to monetary instruments to meet the target inflation level.

All these instruments help central banks achieve their goals, yet they also create the conditions for emergence of other problems. As a result of the activity of central banks, the global economy has become more dependent on the stimuli they provide.

Quantitative easing, introduced as a measure for crisis management, has become an instrument utilized on a regular basis. Today, modern central banks act as not only lenders of last resort, but also as active participants in sovereign and corporate bond markets. In this regard, they face the question of whether transforming quantitative easing into a standard instrument of macroeconomic management is expedient.

The global crisis of 2008-2009 and the debt crisis in the EU changed the understanding of the basic tasks of central banks. Before the crisis, experts believed that a central bank should focus on price stability and sustainable economic growth. This approach urged regulators to ignore the accumulation of systemic imbalances in the financial sector and their related risks. After the crises, authorities achieved a consensus regarding the need to pay more attention to macroprudential supervision based on the analysis of systemic risks and aimed to prevent financial crises. Financial stability has become the second priority objective of a modern central bank. And some central banks even equalized it with price stability goal.

Modern information and other technologies also significantly affect the banking activities, thus changing the nature of the banking system. High capital requirements and strict regulations increasingly push traditional banking business toward so-called "shadow banking". Accordingly, such activities as virtual currency, blockchain applications, crowd funding, and P2Plending do not only reflect the tendency towards increasing efficiency and creating innovative business models, but also raise the issue of supervision on the part of regulators. 
Hence, the NBU organized the first Annual Research Conference of the NBU (in collaboration with Narodowy Bank Polski and with the support of the Government of Canada and the Kyiv School of Economics) to consider these issues. Or, in other words, to provide an answer to the question, "what is a central bank of the future?" as NBU Governor Valeria Gontareva noted. Particularly, in her opening address, the NBU Governor described the transformation processes taking place in the Ukrainian financial system and within the NBU. Ms Gontareva also emphasized that, given the rapid pace of change in its transformation, the NBU should focus not only on the current state of the world's leading central banks, but also on the vision of their role in 5-10 years.

The conference included five research sessions and three policy panels, as well as the key speaker's Keynote lecture and separate Opening remarks of the second day.

\section{RESEARCH SESSION 1. PRICE SETTING}

Oleksiy Kryvtsov (Bank of Canada) opened the first research section with the presentation of the paper Price Selection, Inflation Dynamics, and Sticky-Price Models, written in collaboration with Carlos Carvalho (Pontifical Catholic University of Rio de Janeiro). In this paper, the authors analyzed the applicability of two canonical models price setting (Calvo and GolosovLucas) to explain the fluctuations of inflation in the UK using a large array of micro price data.

Expanding the classical view of inflation, as a result of price selection, which depends on the margin of prices that vary during the period, and on the average amount of price changes, the speaker suggested extend the usual decomposition by breaking the intensive margin into additional components, namely the average level of newly set prices (reset component) and their average level prior to adjustment (preset component).

According to the research, inflation in the UK weakly correlates with the preset price level, which accounts only for about $16 \%$ of inflation variance. Accordingly, inflation is mostly driven the adjustment of prices from below-average levels.

Asked about the impact of competition level on price setting, Kryvtsov noted that the extension of the model to account for the impact of market concentration is possible, for example, in the analysis of various product groups in various sectors. The result may be the discovering the existence of differences in price setting for different groups of goods and/or in sectors, depending on the level of market concentration.

Oleksandr Talavera (University of Sheffield) presented the Price Setting in Online Markets:' Does IT Click? research work carried out with co-authors Yuriy Gorodnichenko (University of California, Berkeley \& NBER) and Vyacheslav Sheremirov (Federal Reserve Bank of Boston). In the presented paper, the authors experimentally investigated the features of price setting in online markets, which theoretically should be more flexible than in standard markets. According to the authors, this is attributable to such factors as the relative ease of tracking nominal prices, the effectiveness of online services for goods searches and price comparison consumers utilize to independently monitor goods and analyze the existing prices.

The results of modeling presented in the report showed that pricing behavior in online markets had the same drawbacks as standard markets - rigidity of prices and significant variance. However, the features of price setting in online markets may explain the reaction of sellers to external shocks, e.g., sellers tending to change prices in periods of high demand that coincide with US holidays such as Christmas, Thanksgiving, etc. The authors also confirmed their assumption about the short-term nature of seasonal price surges.

During the discussion, participants agreed that the role of the online market's importance continued to grow, and the use of special tools for collecting and processing online data had the potential to become an effective instrument for central banks to monitor and control inflation.

Anton Nakov (European Central Bank) presented a paper co-written with Luca Dedola (CEPR) entitled State-Dependent Pricing and the Paradox of Flexibility. The key question posed in the paper tested whether an increase in price flexibility is a factor of macroeconomic stabilization. The speaker presented the results of modeling the influence of state-dependent price setting on the eeffectiveness of macroeconomic stabilization, and analyzed the characteristics of the Calvo model and the fixed menu cost model.

Among the main results of the modeling, Nakov pointed out the following: 1) in the absence of IT, the state-dependent price setting model causes more destabilization than the Calvo model; 2) a higher level of price flexibility determines a higher destabilizing impact; and 3) the paradox of flexibility is not just an artifact of Calvo pricing model. The main conclusion of the research is that the main factor for ensuring macroeconomic stability is monetary policy that controls inflation processes in the economy. 


\section{RESEARCH SESSION 2. MONETARY POLICY RULES}

Roc Armenter (Federal Reserve Bank of Philadelphia) stated that nominal targets have taken center stage in the design of monetary policy during his presentation of the research work titled The Perils of Nominal Targets. Inflation, price level, or nominal GDP may be such nominal targets. Inflation targeting has proven successful at curbing high inflation in both developed and developing economies. Armenter named Israel and Poland as examples of success. However, now these countries have a problem of inflation being less than the target in long-run.

In his research, Armenter raises the issue of capability of IT to overcome very low inflation. He considers a Neo-Keynesian model in conditions of the interest rate approaching the zero lower bound.

The main conclusion of the research is that central bank's commitments to nominal targets are a necessity, but not a sufficient condition to achieve the targets. Despite interest rates being at the zero level bound, inflation expectations have remained mostly anchored.

However, once economic agents' trust that the central bank can bring inflation growth to the target level disappears, the central bank would find itself unable to implement the target and restore confidence. Contrary to previous developments in this area, Armenter believes that the use of nominal targets such as level prices does not solve the problem of bringing expectations to the target level.

Armenter sees a possible solution to the problem of anchoring expectations in setting targets for long-term nominal interest rates. The consequences of such a change in the operational toolkit of central banks, in particular, for financial stability, fiscal stability, and the pension and insurance systems, were the subject of discussion during a series of questions and answers on the results of the report.

Further, Carlos Viana de Carvalho presented the research study titled Anchoring Inflation Expectations conducted in collaboration with Stefano Eusepi (Federal Bank of New York), Emanuel Moench (Deutsche Bundesbank), and Bruce Preston (University of Melbourne). The authors analyzed the issue based on a model of long-term inflation expectations, which are key to the success of monetary policy under IT.

In his presentation, the speaker demonstrated examples where expectations were anchored and when they were unmoored as a result of shocks. In equilibrium, actual inflation is a result of consolidated expectations of economic agents and households. If they believe that the long-term component affects the current inflation directly, expectations about the future are projected onto the current state. So, expectations are partially self-fulfilling, producing an endogenous inflation trend. An important feature of the model is the sensitivity of inflation to forecast errors. If economic agents conclude that actual inflation significantly differs from the expected level, in other words, the forecast errors are obvious, they will not take into account the previously forecast targets but will be guided by new inflation data.

The model also describes the evolution of long-term expectations, and its practical application demonstrates that forecasts proved true for most countries where tested. Using examples from many countries, the authors confirmed the effectiveness of the model for forecasting, especially considering the data about times when economic agents changed their expectations and what kind of short-termed data they used in the regime of changing expectations.

Key findings of the research: to successfully implement an IT regime, the central bank should utilize the most recent actual data and update the forecast in case new shocks occur. Some deviations from the forecast are exogenous in character, and they partially depend on macroeconomic policy. Under the influence of misconceptions about the inflation level and the impact of shocks, economic agents change their behavior and expectations. Under these circumstances, monetary policy must take into account changes in expectations and influence the formation of long-term inflation expectations based on new data.

\section{Maurice Obstfeld's Keynote Lecture}

On the first day of the conference, the Chief Economist at the International Monetary Fund, Dr Maurice Obstfeld, presented the Keynote Lecture: Trilemmas and Tradeoffs: Living with Financial Globalization. He considered two views on monetary policy in small open economies. According to the first view, a small open economy policy under conditions of a flexible exchange rate is not qualitatively different from a closed economy. Despite external economic shocks, the central bank, using the exchange rate as a buffer, enjoys monetary autonomy and can ensure the performance of internal objectives, inflation in particular. According to the second diametrically opposed view, countries with a small open economy in the globalized world enjoy no monetary autonomy, regardless of their exchange rate regime due to the impact of financial cross-border flows. These financial flows are determined by economic cycles and the policy of central banks from influential countries, primarily the United States. 
The speaker emphasizes that each approach has its own rationale. However, as the results of empirical studies on panel data of a large sample of countries demonstrate, changes in short-term interest rates in small open economies hardly depend on changes in interest rates in major countries. Internal factors often determined interest rates. This means that countries with flexible exchange rates can afford a certain level of monetary autonomy. At the same time, for various reasons, these countries are also concerned about the issues of exchange rate management. This again puts countries into the classical trilemma of choosing between the free movement of capital, exchange rate stability, and monetary autonomy to achieve internal goals. In fact, countries with small open economies have to make a tradeoff in finding the optimal choice between these objectives.

A similar trilemma exists inherently in the financial system: countries cannot simultaneously afford financial stability, free cross-border financial flows, and national control over supervision and regulation of the financial system. The development of the banking crisis in the euro area proved this.

Finally, Obstfeld emphasized the importance of international cooperation and coordination through the interconnectedness of financial markets and the complexity of the international financial system. Thus, despite all uncertainties associated with flexible exchange rates, Obstfeld holds a deep conviction that it should be a choice by central banks that have internal targets. Moreover, to ensure financial stability in addition to the adequate monetary policy, countries should apply macroprudential regulation with particular efficiency. In this way, the efforts of national regulators only may be insufficient to achieve results, so international coordination and collaboration in this area should deepen. This will be facilitated by the Financial Stability Board and the Basel Committee, which allow for improving the quality of macroprudential supervision at the international level.

Answering questions during the follow-up of the report, Obstfeld pointed out the important role of structural reforms, without which monetary policy or macroprudential regulation are only the "second best" instruments. Additionally, while outlining the role of the IMF and other international financial institutions, Obstfeld emphasized the importance of countries creating their own protective buffers, including international reserves.

\section{RESEARCH SESSION 3. MACROPRUDENTIAL POLICY AND FINANCIAL FRICTIONS}

Marcin Kolasa (Narodowy Bank Polski) presented the research study Could the Boom-Bust in Eurozone's Periphery Have Been Prevented? carried out with co-authors from Narodowy Bank Polski Marcin Bielecki, Michal Brzoza Brzezina, and Krzysztof Makarski. The authors examined the problem of cyclical dynamics of demand in eurozone countries in recent years, and the optimal macro-prudential policies governing these fluctuations.

The researchers found a significant concentration of internal imbalances in real estate markets in most Eurozone countries, which, in turn, had a significant impact on other sectors of the European economy. As a result, the risks and pressure on the euro exchange rate grew. Analyzing the residential mortgage sector, as a part of the European economy with significant asymmetry, the authors determined that problems in this sector were the catalyst at the onset of the financial crisis in European periphery countries in 2008. Under such conditions, a common monetary policy and a single ECB key interest rate for countries with different economic structures and development of their financial markets led to significant macroeconomic imbalances. Authors modeled the optimal monetary and macroprudential policy for the eurozone countries while considering their participation in monetary union and structural differences.

According to the researchers' conclusions, the effective implementation of monetary policy requires flexible management of the key interest rate. At the same time, exclusively utilizing monetary policy instruments of at the level of the eurozone cannot ensure domestic macroeconomic balance of the peripheral European countries. Optimal macroprudential policy foresees the required potential to relax the credit cycle in the periphery countries, thus reducing the impact of imbalances. Effective implementation of these policies provides a solution to the problem of imbalances in the periphery countries of the eurozone. New rules for monetary and macroprudential policy should be optimized in order to avoid imbalances and to create additional buffers to prevent the impact of shocks.

Igor Livshits (University of Western Ontario) presented results from the research paper Sovereign Defaults and Banking, prepared in collaboration with Koen Schoors (University of Ghent). In this research, the scholars presented a model with the assumption about sovereign default using the examples of Russia and Argentina.

The main objective of the research is to develop approaches to prudential regulation to prevent the occurrence and realization of banking risks. The authors examined this question in the context of determining the exposure of assets, particularly for government securities. This is especially important because of the increase in the number of countries where government bonds cannot be classified as low-risk and profitable. Examples include the sovereign defaults of Russia in 1998 and of Argentina in 2001. The speaker emphasized that one of the key causes of the default in Argentina was a change by the government, at the legislative level on the conditions for purchasing government bonds leading to risky speculative activities by banks. 
The main conclusions based on the results of the research lie in the necessity of providing high-quality prudential regulation. If high-risk government bonds in the market are considered to be safe, it leads to increased risks in the banking system and becomes the cause of the banking crisis. Under the condition of proper prudential regulation and the absence of excessive debt, the risks of sovereign default are minimal.

Concerning the prudential supervision under different conditions and patterns of central banks, the researchers found that important factors of quality and efficiency of macro-prudential regulation are imbalances (risky governmental policies, banks, etc.) that provoke a crisis. In their research, the authors point out different approaches to prudential regulation that will enable advance detection of high-risk speculative activities in the banking sector. Summarizing the results, Livshits said that prudential regulation must be realistic, establish the dependence of the capital adequacy coefficient on the volume of investment in government bonds, and consider all potential risks.

\section{POLICY PANEL 1. CAPITAL FLOWS MANAGEMENT}

NBU Deputy Governor Oleg Churiy opened the first Policy Panel with a presentation entitled Ukrainian Experience With Capital Account Liberalization. He pointed out that 20 years ago, control of capital movement was considered an anachronism and the free movement of capital was seen as the best solution for countries that had limited capital. The financial crisis clearly demonstrated that complete rejection of control over capital flows was premature. Managing capital flows currently is an instrument to ensure financial stability. Therefore, it is no substitute for conducting macroeconomic reforms, but strict measures allow short-term stabilization of the situation and the ability to buy time.

The speaker outlined three main priorities according to which liberalization of capital movements will be implemented in Ukraine. The first is to promote economic growth and production, particularly through liberalization of foreign direct investment and the current account. The second is the development of the financial market and increasing its liquidity. The central bank has gradually shed its function as a principal market participant and became the market controller. The third is to attract long-term equity and debt capital, and to increase Ukrainian investment abroad in the long-term perspective.

Regarding the strict administrative measures on the foreign exchange market introduced in recent years, Ukraine's experience of capital flows regulation can be used only in extraordinary situations. All measures taken by the central bank were appropriate to the situation in the country's economy. The central bank can apply some restrictive measures on capital movements even after the transition to a more liberal model, but already as macroprudential policy instruments. However, in the case of Ukraine, any restrictive measures are always negatively perceived by the market, despite the fact that they are aimed to limit devastating capital outflows or inflows.

Andrew T. Levin (Dartmouth College), in his presentation on Capital Mobility and the Design of Monetary Policy Frameworks, stressed that central banks should be protected from fiscal dominance or political influence, and they should have operational independence rather than be subordinate to the executive government. A central bank needs to have a legal mandate and clear objectives for policy implementation since it should be accountable to the government and the public. The public should be confident in the actions of its central bank to successfully implement policy, particularly in key strategic decisions.

The speaker pointed out three basic principles that are of importance for the implementation of monetary policy for a very wide range of countries from low-income countries, to developing, and the most developed countries.

The first fundamental objective of a central bank of a country with its own currency is to maintain the stability of its currency and high public confidence therein. This means price stability, and, consequently, anchoring of inflation expectations, which is expressed in the presence of medium and long-term goals. The population must understand that goal and see that the actual inflation rate is gradually approaching the target rate. The experience of many central banks, including New Zealand's central bank, showed that the concentration of efforts just on an inflation target in the short-term is a mistake because central banks have to achieve multiple objectives simultaneously, including to support economic growth and improve living standards.

The second principle is that a central bank should conduct interventions on the foreign exchange market only in case of an emergency. Its intervention should be transparent and systematic, and can only be justified in exceptional cases where it is necessary to smooth out a high amplitude of exchange rate fluctuations.

The third principle states that the use of macroprudential instruments is critical, no matter who applies them: the central bank, the government, or other public institutions. This principle is crucial to financial stability and ensures that monetary policy does not contradict the fundamental objectives of financial system stability.

Thus, an important part of the implementation of a central bank's policy is effective communication with the public and raising public awareness in implementing monetary policy, exchange rates, and operational independence, as well as justification and explanation of its decisions. The speaker stressed that a central bank should have at its disposal a variety of plans to minimize risks in different circumstances. 
Marek Dabrowski (Bruegel), in the presentation on Managing Capital Flows in a Globalized Economy, stressed that the barriers to capital flow slow down economic development in a global context. In his view, constraints on capital flows cause damage to small and medium enterprises, and affect large companies to a much lesser degree.

The speaker considered the two most important implications of actually fully-open capital markets for balance of payments and monetary policy.

Traditionally, prior to liberalization of capital movements, experts focused their attention on the current account, issues of competitiveness, trade policy, and the exchange rate. Only at the next stage the problem of financing the current account deficit was raised. Once the time for the free movement of capital came, causality relationships reversed. Now, the movement of capital is exogenous in nature, while the current account is adjusting to changes in the financial account through the exchange rate. Thus, recent currency crises in CIS countries are attributable to the outflows in the financial account. Therefore, the question arises: if there are no instruments to control capital flows in countries, how can the capital account be affected otherwise? According to Dabrowski, such leverage exists, but their influence is very limited and unpredictable. These instruments include macroprudential regulation and monetary and fiscal policy.

As for monetary policy, issues related to free movement of capital lie in the fact that the monetary supply in a country is becoming a largely dependent variable. Moreover, significant exchange rate fluctuations provoke unintended and unwanted adverse effects on financial stability, competitiveness, and the real economy, and in cases of significant depreciation reduce confidence in the domestic currency. In addition, the majority of the world's economies are influenced by monetary decisions of the Federal Reserve System and the European Central Bank, which lead to increased volatility of capital flows and imported inflation.

Linda L. Tesar (University of Michigan), in her presentation entitled Weighing the Costs and Benefits of Capital Market Integration, tried to answer the question of how the financial crisis forced us to rethink the capital market integration.

She identified three main factors among the potential benefits for capital market integration. The first is a gain in efficiency, which is to stimulate the outflow of capital from economies with a capital surplus to economies that need it the most, thus reducing capital costs. Moreover, the efficiency in the financial sector increases as a result of higher competition. The second factor is increased stability thanks to smoothing fluctuations in the national income (consumption), a higher level of diversification and risk management, better "market discipline," and facilitating better information exchange. The last positive factor is higher economic growth through savings mobilization, increasing profit rates, aligning revenues with relatively more developed countries in the short-term, and the exchange of technology through an investment in the long-term.

However, contrary to the theory, capital redistribution between developed countries and developing countries did not occur after the liberalization of capital movements. The majority of capital flows continue to pass through developed countries. Moreover, easing of consumption fluctuations in developing countries was very limited; capital flows in these countries are generally pro-cyclical, so they even increased volatility.

The latest global crisis has confirmed the relationship between the degree of openness of financial markets and vulnerability to external factors such as sudden stops, currency crises, the effects of contagion, and a lack of lenders of last resort. Thus, the role of the financial sector needs to be rethinking, as it was the main source of instability in developing countries, but developed countries still did not consider such risks. Also, taking into account all the potential benefits, the role of capital controls must be revised. Governments should give more attention to financial regulation and global cooperation, the role of public debt, and the efficiency of the financial sector, but prudent public policy should be paramount.

\section{Philipp Hildebrand's opening remarks}

Vice Chairman of BlackRock investment company, Philipp Hildebrand, opened the second day of the conference with his presentation Are Central Banks Out of Ammunition? Its main point is to evaluate how effective the actions of the central banks in developed countries are in conditions of low inflation and weak economic growth.

A special feature of the current economic situation in developed countries is extremely low inflation, which did not exceed $2 \%$ per year starting from 2013. Recognizing that maintaining the inflation rate at the desired level is necessary for economic growth, central banks combined keeping key interest rates at zero, in some cases even at a negative level within their assets redemption programs. This policy was effective since almost all developed countries showed signs of recovery in economic activity, which was a result of financial conditions easing. In addition, these central banks' actions prevented a turn in price and wage deflation in these countries, which combined with high levels of public and private debt would have had really disastrous consequences for their economies.

Nevertheless, inflation in developed countries has remained at an extremely low level for very long periods of time. Even more important is the fact that market interest rates also continue to decline, which significantly increases the amount of the 
sovereign debt market with a negative yield. This situation is largely due not only to low interest rates set by central banks, but also both insufficient private and public investments, the volume of which is substantially lower than the current savings. Uncertainty is caused by investors' negative assessments of the level of future income that can be derived from investments.

What are the scenarios for ending low interest rates and the deflationary period?

The first scenario involves actual continuation of the current situation, the main feature of which is the surplus of savings over investment for a long period of time. Such an economic state is characterized by low economic growth, inflation, and interest rates, which may cause a new price "bubble" on certain assets. However, gradual recovery of the US and German labor markets, the countries most affected by the crisis, indicates the probability to exit the recession through acceleration of investment activity.

The second scenario assumes a recession exit with the aid of prudent fiscal incentives and, more importantly, structural reforms that stimulate investment growth.

Summing up the speech, Hildebrand noted that the result of central banks' activities is the development of prerequisites for economic growth in the country. However, these efforts must be supported by appropriate government policies. Otherwise, central banks' actions to overcome the crisis independently may involve significantly more time and effort.

\section{POLICY PANEL 2.}

\section{INSTITUTIONAL BUILDING OF THE MODERN CENTRAL BANK}

Opening the second Policy Panel, its moderator, Marco Škreb, pointed out that the specificity of the central bank's operations changed very rapidly due to the dynamic changes of external environment and associated challenges. Speakers of Policy Panel 2 provided their answers to the questions of what changes should be made and in what manner in order to ensure effective functioning of the central bank, bearing in mind that the central bank in each country is a legitimate monopoly.

The transformation features of the central bank in order to increase efficiency in its activities were outlined in the presentation titled Transformation of the NBU: The Big Bang Practice by NBU Deputy Governor Vladyslav Rashkovan. The NBU was urged to fully reform its activities in the context of deep financial crisis, a sharp drop in GDP, exchange rate depreciation, and the institutional weakness of the banking system. Amid the most important steps the speaker defined were elimination of non-core functions, organizational structure reform, redesign of decision-making processes, and implementation of new approaches, including focusing on the core functions, centralizing many functions, and intensifying the analytical component of decision-making.

The ultimate transformation goal is that the NBU shall become an effective modern regulator and a member of the family of European central banks. A lot has been done to this end, and the NBU is gradually becoming a legitimate professional, transparent organization that enjoys growing public trust, more open to the country and the world.

Rashkovan also stressed that the NBU's mission is to ensure price and financial stability that will promote economic growth in Ukraine. The goals are ambitious, and they are gradually being implemented. The NBU continues working on capital accounts liberalization, implementation of IT, research function development, a clear vision of what the central bank should be like, and changing corporate culture, particularly in defining the mission, vision, and values of the organization. As a result of the transformation, the NBU will become a powerful institution that will have a significant impact on the formation of favorable government economic policy.

Emma Murphy (Bank of England), in her presentation The Role of Culture, Engagement, and Communication Challenges in Transforming Modern Central Banks, considered the development of corporate and organizational culture as a necessary component of the successful operation of a central bank. The Bank of England has a very distinct and strong corporate culture, and all employees are proud to be part of the institution. An integral part of the transformation of a central bank is creating an organizational culture that should be part of the central bank's policy. Employees should have a clear common goal, the achievement of which should unite them. Unfortunately, changing corporate culture is a long-term and painstaking process.

The Bank of England recently developed a mission that unites all goals in one - improve the welfare of British citizens through financial and monetary stability. The mission establishes a single command and determines the central bank's accountability to the public. Shared values motivate people and determine what is most important in their work; they encourage employees to act towards a certain direction. Values also help change the system of quality management. They should be fundamental components ensuring the achievement of the desired result. 
The Bank of England has implemented internal communications to support and implement solutions, such as video broadcasts. Effective internal and external communications is a key component for the successful transformation of the structure and implementation of innovation. The program of implementing changes also requires effective external communications provided by an informational group since the central bank has qualified professional economists who are largely introverts and not effective communicators. Given the fact that some employees may internally oppose changes, they should be involved in the process so that they not only experience these changes by themselves, but also play a role in providing changes.

The specific use and control of central banks' financial resources was examined in The Finances of Central Banks presentation by David Archer (Bank for International Settlements). New challenges facing central banks are prerequisites for changing their structure. First of all, independent funding is necessary to ensure successful reforms as it enables the pursuit of independent policies.

Independent funding secures functional independence. Central banks have to distance themselves from politicians and establish independent sources of financing and funds, as well as pay attention to the impact of weak budget constraints to reduce financial risks. The strong financial position of a central bank is important in terms of ensuring its independence. Each central bank's policy should be analyzed in terms of benefits and its total cost, because the activity of a central bank directly affects the state of public finances. Public financial resources deposited at the central bank are part of the so-called "deal with the public," so the money should not be jeopardized in any case.

As known from practice, under certain circumstances central banks may be insolvent. To prevent this, capital should be accumulated, properly classified, and distributed while the format and mechanism of the recapitalization of the central bank and transfer of financial risks from the central bank to the treasury shall be legislatively regulated (application of non-standard policies involves high risks). In order to establish the political legitimacy for the actions of central banks, there is a need to conduct direct negotiations with the government. When making decisions on capital and liabilities of a central bank, it is necessary to exclude dividend distribution issues (the problem of asymmetric distribution). Archer provided the example of the Swiss National Bank, which took all of these steps, i.e., its case is the best example of the use of a complex system approach to manage their own finances.

At the end of the presentation, Archer said that budget constraints for the central bank were inevitable, but useful as they promote efforts to achieve priority objectives, including ensuring price and financial stability.

Andrei Kirilenko, lecturer of the Imperial College of London Business School, suggested to view his presentation New Technologies, that Central Bankers Need to be Aware of in the prism of a generation of innovation and money circulation in various forms.

Recently, the Bank of England and the People's Bank of China have presented their own development - cryptocurrencies, which gave grounds for global media to state that central banks seized the bitcoin championship. Some central banks provide an opportunity for customers to hold cryptocurrency accounts, which is a leverage distribution technology. As far as a central bank is an institution trusted by market participants, its involvement in cryptocurrency production allows working in a niche, which is now independent of the central market. The regulator can quickly analyze the situation to get information on where cryptocurrency is placed and in what amount. This also allows for quick and efficient distribution of money, conducting unconventional monetary policy, and directing cash flows accurately to where they are most needed.

Kirilenko thoroughly analyzed the functioning of blockchain technology, which provides central banks opportunities employed by other market participants. These technologies are implemented in corporate decisions regarding property rights, and they are increasing in the segment of implementation of verified financial transactions and secure payments. While most central banks ignore the technology, it develops independently of the regulators' influence. Currently, there is no regulatory framework for such technologies, and the attitude towards them differs ranging from neutrality, to interest, to concern, and rejection. The UK and US regulators demonstrate the most practical interest for innovation. For example, the issuance of special bit licenses was announced in New York state.

The speaker drew conclusions as for the availability of objective prerequisites to apply technological innovations in central banks. Building an infrastructure based on blockchain technology payments can reduce expenses, increase the level of trust, and create real competitive advantages for Ukraine. The central bank, if necessary, can be at the head of innovation that provides a tremendous opportunity for the implementation of monetary policy and financial stability on a new basis using new instruments.

When asked about the prospects for the development of an open-source platform and launch of cryptocurrencies and their exchange by different countries, the speaker underlined that blockchain technology and the corresponding Internet protocol that ensures its operation is a revolutionary way to store and transmit value rather than to store and transmit information about a certain value. These technologies are changing lives as they have great potential. Therefore, the natural solution is not prohibition, but joining this process and using its potential, particularly open-source technology, which provides all participants with an opportunity for consensus on the system architecture. Participation in such a consensus is not a matter of the distant future and can be a starting point to ensure financial stability on a brand new platform. 
The speaker also referred to a quote voiced by Larry Summers during a conference at the US Department of Treasury that central banks could soon be comparable with the private sector in terms of currency issuance. This can lead to negative or zero interest rates for a long time since competition evolves between the public and private sectors in the issuance various forms of currencies that are demanded and trusted in a modern world, i.e. are capable of operating autonomously on certain platforms in certain communities, such as the Internet environment. In this context, central banks have faced the real challenge of monopoly on the issuance of various forms of money in circulation. Central bank has a choice to respond to the challenge with a ban or to act proactively by mastering new technologies.

\section{RESEARCH SESSION 4. ISSUES IN MONETARY TRANSMISSION MECHANISM}

The fourth research session was opened by Oleksandr Faryna of the NBU, who presented the research work titled Exchange Rate Pass-Through and Cross-Country Spillovers: Some Evidence from Ukraine and Russia. The issue of the impact of the exchange rate pass through is of particular importance for countries with small open economies, including Ukraine, characterized by high sensitivity to external disturbances.

The issues of direct and indirect effects of exchange rate pass through in theoretical and empirical studies are considered as "isolated islands" where the impact of external shocks on domestic prices is one-sided, and the probability of transmission of the shocks between countries is not taken into account. Meanwhile, the financial and economic relations between countries are characterized by close trading, financial, and other relationships that have an impact on the extent and value of the effect of the exchange rate pass through. In particular, strengthening of the exchange rate in accordance with theoretical assumptions helps to reduce the price level in one country, and the depreciation processes that evolve at the same time in another country aggravate inflation. At the same time, the growth of domestic prices in one country entails the growth of prices for imported goods to another and thus compensates for the effect as a result of appreciation.

Faryna proposed a bilateral vector autoregressive model that allows for considering the effect of transferring the exchange rate based on market and foreign trade relationships between countries using the example of Ukraine and Russian Federation. According to the research results, cross-country spillovers should be considered where the effect of transfer of the exchange rate for Ukraine is evaluated. In particular, the result of the Russian ruble depreciation against the hryvnia is an increase in domestic prices in Ukraine, indicating the presence of additional trade spillover channels. In addition, according to the alternative model, which includes the ruble and US dollar exchange rates, it was found that the ruble depreciation is a source of weakening of the hryvnia, including through joint competition on foreign markets. Considering the results, the NBU should also take into account the influence factor of the Russian economy on Ukrainian consumer prices when making decisions to achieve inflation targets.

Bartosz Maćkowiak of the European Central Bank presented the research work Monetary-Fiscal Interactions and the Euro Area's Malaise in collaboration with Marek Jarocinski (ECB). The most important issue raised in the research is the relationship between monetary and fiscal policies and their impact on macroeconomic results in the eurozone during the "great recession".

In their research, the authors apply a simple general equilibrium model with rigid prices and a single monetary regulator that aims to achieve inflation targets and acts in accordance with the Taylor Rule subject to the lower border of the interest rate. However, the model takes into account two fiscal authorities which refer to the countries of the "North" (Germany, France, the Netherlands) and "South" (Italy and Spain) for simplification and assume the default probability of their debt securities. Fiscal authorities are seeking to stabilize the debt level by means of correcting the primary budgetary balance and experience default in cases of excess in the level of debt on a certain upper limit. According to the authors, this simple model specification allows for displaying the basic features of implementation and coordination of monetary and fiscal policy in the eurozone, as evidenced by the results of the simulation of the model and their similarity with historical data.

Proceeding from the basic model, the authors conducted an experiment that provides for an alternative method of coordination of monetary and fiscal policy. The main feature of the alternative model specification takes into account the involvement of a new centralized pan-European institution that has the authority to buy debt securities of certain financial institutions and also issues its own debt securities (payments on which are ensured by the monetary regulator, so there is no risk of default on such securities). Thus, in the case of achieving the lower border of the key interest rate, monetary policy becomes passive and fiscal institutions act in accordance with established functions of fiscal policy reactions and increase the primary budget surplus in accordance with the general debt level in the eurozone. The experimental model's results showed that the use of the suggested approach to the coordination of monetary and fiscal policy would considerably improve macroeconomic results and avoid a long period of recession in the eurozone.

In his report entitled Rules Versus Discretion in Monetary Policy Conduct. Lessons for Ukraine, Alex Nikolsko-Rzhevskyy (Lehigh University) considered separate approaches to monetary policy and outlined the main advantages and disadvantages 
of their adoption in Ukrainian realities. In particular, the author compares monetary policy based on the established rules and discretionary policy where the monetary regulator is more focused on current economic conditions than on predetermined rules.

As the speaker noted, the system of rules applied allowed for increasing the transparency of the monetary regulator and secure long-term inflation expectations on one hand. In this context, the Taylor Rule, which implies a change in the interest rate in response to deviations of inflation from target level and the actual level of output from its potential, is classical. Discretionary policy, on the other hand, is more flexible, can include a much greater spectrum of information, and is independent to structural changes in the economy. A comparison of these approaches occupied a central place in macroeconomic studies that were intended to answer questions about the effectiveness of rules and discretion in certain historical periods. However, existing studies determine such periods mostly in an exogenous and subjective manner, and that is why evaluations of the effectiveness of certain approaches are contradictory.

Using the US Federal Reserve policy as an example, the author endogenously separates the periods of minor deviations of the US Federal Reserve rate from the calculated value of the interest rate in line with the classic Taylor Rule, which correspond to "rules periods", as well as the periods of significant deviations being considered as "discretionary periods". The researcher assessed the effectiveness of monetary policy in these periods based the loss function, and the results obtained were better in periods when monetary rules were used rather than in periods of discretionary policy.

In his opinion, the findings can be used to form an effective monetary policy in Ukraine. Despite the reform and purification of the banking sector, IT implementation, updating and simplifying the instruments of monetary policy, the main challenges for the NBU remain relatively high inflation expectations, significant differences in regional development, lack of trust in the monetary regulator and a false understanding of the goals of monetary policy by investors and the public. The establishment of a monetary rule will help improve confidence in the regulator and the transparency of monetary policy, reduce political pressure on the NBU and fix inflation expectations.

Following the report during a question and answer session, the participants discussed to what extent a central bank's policy, based on IT regime (including the NBU), can be considered discretionary. According to the speaker, for a central bank to be classified as one that applies strict rules, public awareness and approval of such rules is necessary. However, according to representatives of central banks using IT, raising public awareness of the goals and explaining changes in their operational instruments already implies following monetary policy rules.

\section{POLICY PANEL 3. CHALLENGES FOR INFLATION TARGETING}

Opening the third Policy Panel, its moderator, David Vavra of OGResearh, noted that IT regimes proved successful not only in developed countries, but also in emerging market countries. In his opinion, Ukraine's accession to the club of countries with an IT regime is the right step.

For almost 30 years of IT regimes, its basic characteristics remained unchanged: quantitative inflation target, institutional independence and transparency of the regulator, and a flexible exchange rate of the national currency. However, the macroeconomic environment changes with time, so IT implementation is country-specific.

NBU Deputy Governor Dmytro Sologub, in a report titled NBU in the Transition to Inflation Targeting, outlined how the central bank should implement the new monetary regime.

In his view, the transition to IT was the only way out of the crisis, which was the result of almost twenty years of fiscal dominance and fixed exchange rate of hryvnia. However, the introduction of IT did not start from scratch. Some developments took place, but there was lack of political will to implement IT. Sologub thanked colleagues from Canada, New Zealand, Poland, the Czech Republic, and Sweden for sharing their experiences in decision-making at the central bank and the assistance in implementing the necessary changes.

One of the main results of the NBU's work in the past 12 months is development of a strategy for implementing the IT regime and publishing the objectives of the NBU. The approved strategy is already bringing positive results: inflation is gradually decreasing and getting closer to target levels. By the end of 2016, consumer inflation in annual terms should be about $12 \%$, and about $5 \%$ by the end of 2019. The system of decision-making has changed with the newly established Monetary Policy Committee operating effectively. The process of developing an effective monetary transmission mechanism is ongoing; operational design of the interest rate policy is qualitatively changing.

The practice of implementing an IT regime in Ukraine shows that its success is largely determined by the presence of political will for change. No countries had fulfilled all the prerequisites for transition to IT. These conditions are usually created during the implementation of the new regime. 
The speaker noted that the impact of the central bank on the economy was not absolute, so structural changes are necessary for the successful implementation of IT. Only comprehensive measures by the government and the central bank will contribute to the achievement of price and financial stability.

The detailed report Inflation Targeting in Emerging World: Lessons from Poland was presented by member of the European Parliament Dariusz Rosati, who was directly involved in the establishment of this monetary regime by Narodowy Bank Polski.

The development of a plan for Direct Inflation Tergeting implementation began in Poland in 1997, immediately after the adoption of the Law On Narodowy Bank Polski. This law granted full independence to the central bank and defined its main objective as ensuring price stability. In 1998, in order to achieve price stability Narodowy Bank Polski established a new body called the Monetary Policy Council. Despite the fact that direct IT was introduced in Poland in 1999, the country maintained a controlled exchange rate of the zloty until 2000.

The conditions for the transition to IT in Poland were not ideal. Years of hyperinflation had passed before IT was implemented. It was necessary to make considerable efforts for a long time to reduce inflationary expectations. The impact of non-monetary inflation was very significant. There was a significant excess of liquidity at the banking system, which hampered the work of the monetary policy transmission mechanism. At certain times, monetary instruments were supplemented by restrictive measures to reduce inflation.

After lowering inflation to a moderate level, an independence of regulator and forecasting were the basis for the further successful implementation of the strategy. To prevent accusations of manipulation, Narodowy Bank Polski published its forecasting methodology. However, since there is no model that would project with high probability all of the possible impacts on the economy, the Monetary Policy Council could always use a flexible approach in determining the level of the key rate. Thus, transparency has been and remains an important part of the success of IT.

According to Rosati, the lessons Ukraine can learn on the Polish experience in implementing IT are as follows: IT proved to be effective in emerging markets. During the early stages of transition economies, inflation is determined mainly by non-monetary factors that reduce the effectiveness of monetary policy. Their effectiveness also depends on the level of monetization and lending. IT is more efficient to maintain inflation in a certain range, not to reduce it from higher levels. The optimal range of inflation targets should not be too narrow to preserve the possibility to pursue a flexible monetary policy. Going beyond the target range negatively affects the central bank's credibility. An obligatory component of successful achievement of inflation targets is consistent adherence to the chosen communication strategy. The bank's policy must focus on the future. The midterm objective is a key component of the strategy, while short-term objectives are complementary.

At the end of the report, Rosati noted that the development of the global financial crisis showed that IT is not a panacea. It is impossible to solve a number of problems in the economy exclusively by regulating the amount of money, in particular to prevent the emergence of "bubbles" in some markets. In his view, such an instrument is insufficient to ensure both price and financial stability. To attain and maintain financial stability, the central bank should probably have more instruments, and, perhaps, for this purpose another independent agency should be established.

Deputy Governor of Sveriges Riksbank Per Jansson presented a report themed Contemporary Inflation Targeting: Time to Change? In the 1990s, economic conditions for the implementation of the IT framework in Sweden were unfavorable. The economy was overheated, salaries and social benefits grew steadily, unemployment was declining, inflation was high enough, people were waiting for depreciation, and the country's debt grew. However, due to implementation of structural reforms, particularly in fiscal policy, the country's economy was balanced. The preconditions for implementation of IT were created. The preparatory period continued for 5 years.

It is also important that a central bank does not complicate the transition to IT. It is particularly undesirable to start public dialogue about a new monetary regime with the publication of inflation reports intended for analysts. Information should be clear and accessible for most people. The information strategy should be reasonable. It needs to be open, but the path to this target should be gradual. Additionally, it is important to skillfully use the trust of society.

Jansson also said, "Do not pretend that you can do more than you actually can". One should avoid generating expectations that are impossible to fulfill since failure will lead to frustration and loss of credibility. It is necessary to develop an action plan in case of deviations from the inflation target in advance. In the case of IT, it is more important to achieve the desired inflation trend than quantitative targets.

After reaching intermediate or ultimate targets, the central bank has to understand that it must constantly maintain the trust of the public and businesses. To this end, Sveriges Riksbank systematically publishes minutes of monetary policy meetings and reports on monetary policy that contain forecasts. Forecasts require particular attention. They should be treated with due care. "You are responsible for all the data you publish. The openness of the central bank and trust from the public ensured the success of IT in Sweden", Jansson said. 
A Canadian Queen's University representative, John Murray, focused on the important aspects of practical implementation of IT in his research study entitled 25 Years of Inflation Targeting: View from Canada. According to him, despite the differences between developed countries and countries with emerging markets, the differences in the implementation of IT by central banks of these countries are not fundamental in practical terms.

In addition, there is no need to overcomplicate the IT regime. "Inflation targeting is really very simple. It only involves being clear, being public, explicit. It is simple and yet very important, because it disciplines your own behavior as a central bank, ensures accountability, and helps to adjust the expectations of the public and businesses. Transparency is an important component of a successful policy," Murray said.

As time has shown, an IT regime proved to be the most effective for Canada (compared to the previous monetary regimes). Murray describes the features of the IT regime in Canada in different periods: before the global financial crisis, in its course, and in post-crisis times.

Canada is the second country in the world after New Zealand, which implemented IT on the advice of the government and one of the first since World War II, that established a flexible exchange rate of national currency. Initially, the process of implementation of IT was criticized and distrusted. Even the IMF believed that the implementation of IT was not a reasonable solution. Over time, the position of society and the IMF changed, but it happened only after the performance of IT exceeded expectations. Declines in production slowed down and interest rates stabilized. The speaker also stressed that one of the prerequisites of IT success in Canada were realistic targets and cooperation between the central bank, the government, and the public.

At the end of the report, Murray considered the feasibility of raising inflation targets. Currently, the prospect of targeting price level is widely discussed among experts. This area has great potential to enhance the effectiveness of monetary policy of the central bank. He also noted that there was evidence that unconventional monetary policy proved effective, and therefore new creative instruments at the disposal of central banks had great prospects.

\section{RESEARCH SESSION 5. ISSUES IN LABOR MARKET AND BUSINESS CYCLES}

Marianna Kudlyak (Federal Reserve Bank of San Francisco) presented the research work Measuring Resource Utilization in the Labor Market in collaboration with Andreas Hornstein (Federal Reserve Bank of Richmond) and Fabian Lange (McGill University, Canada).

The labor market situation is always an area of close attention for the US government both at the level of each state and at the federal level. In particular, the main goal of the US Federal Reserve System is to ensure a high employment rate combined with low inflation. Since 2007, there is a contradictory situation in the US: a decreasing unemployment rate combined with a reduction of participation of labor. Therefore, the question is whether there is underutilization of resources in the labor market in the US. In order to deepen the analysis of this question, the authors developed the Non-Employment Index of Hornstein-Kudlyak-Lange (NEI) based on the results of monthly surveys of 160,000 households conducted by the Bureau of Labor Statistics of the Department of Labor.

The main differences between the NEI and the standard unemployment rate are that the NEI takes into account not only the unemployed, but also persons out of the labor force (persons excluded from the labor force, including the unemployed who have stopped searching for work, pensioners, students, disabled persons, and the rest of the unemployed persons referred to as a separate group). Different groups of unemployed and persons out of the labor force are included in the calculation of NEI with regard to their weight, defined as the probability of the return of these population groups into labor market, including people who work part-time. Studying the probability for each group of unemployed to find a new job allows for the development of a strategy for their further employment.

A direct relationship exists between actual unemployment and NEI. In particular, before 2007 and after 2013, NEI and the actual unemployment rate provided for similar measurement of labor utilization. However, throughout 2007-2013, the actual unemployment rate index overstated the underutilization of labor.

Yuliya Demyanyk (Federal Reserve Bank of Cleveland) presented research in collaboration with Elena Loutskina and Daniel Murphy of the University of Virginia themed Can You Cure Debt With More Debt? High levels of consumer debt significantly contributed to the depth of the recession in 2008 and further held back economic recovery. The basic research questions include: Can the fiscal policy be effective when households are compelled to refuse loans? Is it possible to mitigate the adverse effects of consumers' debt burden? 
As defense spending in the United States ranks third among government spending after the health and social insurance, the research proceeded from the analysis of data on US Department of Defense spending in 1966-2006 (at the level of individual contracts, which included the amount and term of contract, and also the state where the contract was implemented). Defense spending is entirely dependent on political will, so the peaks of such spending occur during periods of military campaigns and are independent of regional conditions. This allows for assessing the impact of fiscal policy on economic growth under conditions of different levels of household debts in each state.

According to model calculations, the fiscal multiplier is higher in the regions with higher levels of consumer debt. Thus, stimulating fiscal policy is effective even with a significant debt burden on households in recession. However, there is not enough evidence that the economy is stimulated through the mechanism of expanding consumption.

likka Korhonen (Institute for Economies in Transition, the Bank of Finland) presented the research work themed Analysis of Business Cycles of China and Its Impact on the Rest of the World, which was done based on a meta-analysis of more than 70 studies by other authors. The main point of the research is to assess the impact of the deceleration in economic growth in China or the Chinese economy's rebalance on the development of other countries.

The research was conducted on two main scenarios: a "hard landing scenario," which involves growth of the share of consumption in GDP by 5 percentage points and a "rebalancing scenario" in which China's GDP growth will not exceed 5\%, and the share of consumption in GDP will increase by 1 percentage point. The "hard landing" will have the greatest negative impact on the GDP of Asian countries and Australia, and a more moderate impact in the eurozone, Russia, and the US. Also among the economic sectors, the most affected are construction, mining, and processing industry, while growth in the service sector and agriculture will accelerate. Thus, China's business cycle closely correlates with the situation in other countries, especially Asian countries and the US. Changes in China will have different effects on the economies of different countries and different sectors, but, as long as China's economy grows, the impact will be positive.

An important channel of China's influence on other countries' economies is the financial channel. Possible liberalization of capital movements by China will have a significant impact on the financial markets of both developed and emerging economies, and for a long period of time. Although global financial liabilities will almost not change, the flow of capital from China to other countries and the inflow of speculative capital into China, as well as change to the size of international reserves can occur. The pure effect is currently difficult to assess, but the portfolios of assets and their relative prices will change. Thus, study of the influence only through the trade channel is insufficient. The spreading of financial vulnerability from China to other parts of the world now is quite likely given the development of financial ties.

Timofiy Mylovanov of KSE made closing remarks for participants. He noted that Ukraine is changing qualitatively and holding the first Annual Research Conference of the NBU evidences this. Ukraine needs high quality economic studies to make informed and balanced decisions. The NBU can be a driving force for their production.

\section{References}

- Armenter R. (2013). The Perils of Nominal Targets. Working Paper, No. 14-2, FRB of Philadelphia. https://doi.org/10.2139/ssrn.2368471

- Carvalho C., Eusepi S., Moench E., Preston B. (2015). In Search of a Nominal Anchor: What Drives Long-Term Inflation Expectations? University of Oregon. The Department of Economics. Available at: https://www.philadelphiafed.org/-/media/research-and-data/events/2015/dsge-models-workshop/papers/carvalho_eusepi_moench_preston.pdf?la=en

- Dedola L., Nakov A. (2014). State-Dependent Pricing and the Paradox of Flexibility. ESSIM.

- Fidrmuc J., Korhonen I. (2015). Meta-analysis of Chinese business cycle correlation. BOFIT Discussion Papers, No. 480, Bank of Finland, Institute for Economies in Transition.

- Gorodnichenko Y., Sheremirov V., Talavera O. (2014). Price Setting in Online Markets: Does IT Click? Working Papers, No. 20819, National Bureau of Economic Research, Inc.

- Hornstein A., Kudlyak M., Fabian L. (2014). Measuring Resource Utilization in the Labor Market. Economic Quarterly, Federal Reserve Bank of Richmond, Issue 1Q, pp. 1-21.

- Livshits I., Schoors K. (2009). Sovereign Defaults and Banking. University of Western Ontario. Working Paper.

- Nikolsko-Rzhevskyy A., Papell D., Prodan R. (2013). (Taylor) Rules versus Discretion in U.S. Monetary Policy. Working Papers, No. 2013-198-44, Department of Economics, University of Houston.

- Obstfeld M. (2015). Trilemmas and tradeoffs: living with financial globalization. Working Papers, No. 480, BIS. Available at: https://www.bis.org/publ/work480.pdf 


\title{
Institutional Set-Up and Mandates of Macroprudential Authorities: International Experience and Benchmarks for Ukraine
}

\author{
Andriy Danylenko \\ National Bank of Ukraine
}

\author{
Viktoriia Sanzharovska \\ National Bank of Ukraine
}

\begin{abstract}
Defining macroprudential authority is one of the key steps in ensuring financial stability. Within the framework of general principles defined by international institutions lie various versions of macroprudential architectures realized by individual countries. Such solutions were shaped by the level of the financial system's sophistication, the government's role, and the central bank's mandate. Yet the dominating trend is to entrust the macroprudential mandate to a central bank, especially if it already has a wide mandate for supervision and regulation of the financial sector. This is especially typical for emerging markets. In most of the reviewed countries, central banks apply macroprudential instruments. The analysis of specificities of the Ukrainian bank-dominated financial system ${ }^{1}$ as well as of international practices points to the most rational solution: to affirm legally the National Bank's macroprudential mandate in the nearest future. Cooperation within the Financial Stability Council should also be further enhanced.
\end{abstract}

\section{JEL Codes: G280, E580}

Keywords: macroprudential mandate, macroprudential authorities, central bank, interagency financial stability boards

\section{INTRODUCTION}

Demand from businesses and the public for financial stability was a legitimate reaction to the global crisis of 2007-2009. We see "financial stability" as a state in which the financial system is capable of performing its key functions efficiently and smoothly, i.e. financial intermediation and arrangement of payments, thus contributing to sustainable economic growth and resilience to crises' impact on economy. Or, as Garry J. Schinasi (2006) summed it up, many researchers define financial stability as the "absence of financial instability."

In order to achieve financial stability, appointed (or newly established) authorities design and implement macroprudential policy (MPP). In other words, the authorities execute a macroprudential mandate (MPM). As we speak of public authorities, their objectives and rights should be laid down in laws (or other legal acts or regulations) according to the basic principle of public law: a public authority can do only those things that it is allowed to do by a body of laws.

Through the last decade, both developed and emerging market countries searched for the optimal framework of bodies responsible for financial stability and reflect this solution in legal acts. It is hard to evaluate these solutions yet: the time that has passed since their implementation is usually too short. ${ }^{2}$ Additionally, there are no commonly accepted units or systems to measure financial stability.

\footnotetext{
${ }^{1}$ Also referred to as bank-centric; that is, banks control the prevailing share in the financial system assets, dominate on capital markets, and distribute the largest proportion of savings in the economy.

${ }^{2}$ There have been certain works lately dedicated to attempts to measure MPP efficiency. The authors tended to concentrate so far mostly on analysis of individual country experiences or efficiency of certain instruments. However, there a new works (Bruno, Shim, and Shin (2015) and Akinci and Olmstead-Rumsey (2015)) that indicate the topic drives attention and is promising for further research.
} 
The need for ensuring financial stability at the global level promoted recommendations on MPM and macroprudential authorities from dedicated international organizations. In particular, the European Systemic Risk Board (ESRB), which is a part of the EU's Single Supervisory Mechanism, and the Financial Stability Board (FSB), a discussion forum of the G20 devoted to consideration of risks and ways for their mitigation at the global scale, should be mentioned. Other international organizations like the IMF, World Bank, and Basel Committee on Banking Supervision also pay close attention to MPMs.

This article attempts to look into a variety of national solutions and international recommendations on the development of macroprudential authorities, to outline global trends and norms, and to compare them with Ukrainian practices.

\section{DEFINING THE MACROPRUDENTIAL MANDATE: LITERATURE AND RECOMMENDATIONS REVIEW}

Previous studies on various MPP aspects established solid grounds for dialogue on MPM and macroprudential authorities. A lot of attention focused on analysis of system of macroprudential authorities/institutional macroprudential framework in works by Borio (2009), CGFS (2010), Goodhart (2011), Ingves (2011), Nier (2009, 2011), Nier and Tressel (2011), Viñals (2011), Nier et al. (2011), Lim et al. (2013), and Brockmeijer et al. (2013). The authors substantiated the need for a clear definition of macroprudential authorities, outlined principles for their work, and considered different configurations of the mandate's distribution between organizations - both with and without an interagency financial stability board.

Macroprudential instruments and application thereof were reviewed in a number of works, e.g. by Borio and Shim (2007), Lim et al (2011), Nier and Osiński (2013), ESRB (2014), Claessens (2014), and Akinci and Olmstead-Rumsey (2015). The works contain recommendations on possible sets of macroprudential instruments, and conditions and objectives for application of each of them.

It should be noted separately that, in spite of the wide use of terms "macroprudential mandate" and "macroprudential authority," inter alia in regulations (including international ones), there is little consensus among researchers across the world on the exact content of these terms. However, the link between these two categories is beyond doubt: "macroprudential authority" is an organization, a board, or a committee that possesses an MPM within a given jurisdiction (while there are still different opinions regarding the real meaning of "macroprudential mandate").

Researchers from the IMF (Osiński, Seal, and Hoogduin, 2013) tend to view the MPM as a right for macroprudential policy. A group of researchers under the Governor of the Swedish Riksbank proceeded from the same understanding (2011). Financial regulators in Slovenia and Cyprus share this vision.

At the same time, researchers from the IMF in several works treat the mandate for ensuring financial stability also as the MPM. The French High Council for Financial Stability has rather resembling views.

On the other hand, experts from the Institute for Monetary and Economic Studies, Egawa, Otan, Sakiyama (2015), differentiate between the terms "financial stability mandate" and "macroprudential mandate." Unfortunately, they do not offer their understanding of the latter term.

The authors of this research tend to distinguish between macroprudential mandates and mandates for ensuring financial stability. They also support the point of view of those researchers who believe that the MPM covers the rights and obligations of a regulatory authority to design and implement MPP.

In spite of these discrepancies in terminology, the process of affirmation and refinement of MPMs gathers steam on a global scale. Back in 2009 at the G20 Summit in London, leaders of key world economies undertook in their final declaration to amend regulatory systems to ensure that authorities "are able to identify and take account of macro-prudential risks across the financial system'. The agenda also included development of macroprudential tools. Basel Committee's Core Principles for Effective Banking Supervision (2012) also mentioned macroprudential authorities and some of their competences.

The EU has advanced the most in setting rules on national macroprudential frameworks and mandates of macroprudential authorities - mostly due to the need to ensure financial stability within the whole integration block. The ESRB was established as a macroprudential authority at the EU level and the ECB received certain macroprudential powers as well. Thus, the ESRB outlined in its recommendation of 2011 the requirements for macroprudential authorities in the EU at the national level. In particular, it emphasized the need for a clearly designated macroprudential authority (a single institution or a board) at the national level and stressed the need to ensure a leading role for a central bank in this framework (especially where the bank is responsible for supervision). 


\section{COMMON FEATURES AND PARTICULARITIES OF NATIONAL MACROPRUDENTIAL MANDATES}

The results of this research covering $67^{3}$ countries from different regions across the world show various national approaches to designation of authorities with an MPM. These decisions were largely conditioned by traditions that existed in financial regulation and public administration in general; they also depended on the structure and specific features of domestic financial markets. In particular, among significant drivers can be a bank-dominated financial system, high institutional capacity building, and independence of the national bank, as well as trust to this central bank.

In regional terms, the following trends were observed (see Figure 1).

\section{Figure 1. Macroprudential authorities (geographical dimension)}

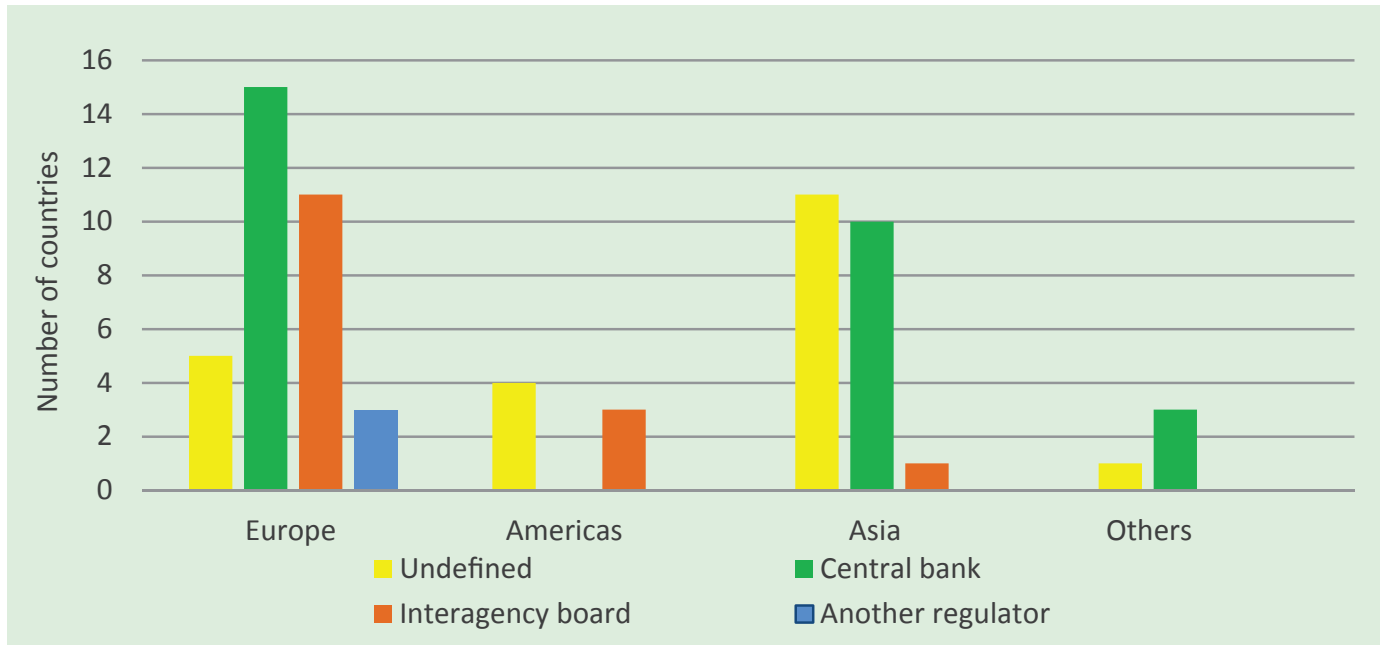

There are not so many countries in Europe where the situation with an MPM remains unsettled. In some of those countries, like Italy and Romania, the respective draft laws have already been submitted to parliaments. MPMs are mostly entrusted to central banks or interagency financial stability boards. Europe is also the only region with the case of other financial regulators as designated macroprudential authorities (the Ministry of Finance or financial supervision authorities, FSAs). Nevertheless, these cases are rather exceptional.

In countries of the Americas covered by the research, the macroprudential authority is either an interagency board (USA, Chile) or not clearly designated (Canada, Brazil).

Almost half of the Asian countries covered by the study did not have a clearly designated macroprudential authority. In most cases, where this issue has been already resolved, the MPM is vested in a central bank and only in some to an interagency board.

In the rest of the countries (in Africa, in Australia, and New Zealand), MPMs were mostly vested in central banks.

The following division was observed in terms of levels of economic development (see Figure 2). The highest heterogeneity in designation of macroprudential authority was discovered among developed economies (OECD countries were taken as a proxy). The most frequent are the cases of designation of a central bank or an interagency financial stability board as a macroprudential authority. As was mentioned above, there are also examples of other financial sector regulators with an MPM in this group of countries (predominantly FSAs, and, in Norway's case, the Ministry of Finance). However, in many of these countries the situation remains unresolved.

${ }^{3}$ In the other three countries (Azerbaijan, Kyrgyzstan, and Vietnam), no signs of a legally outlined MPM or macroprudential tools applied were discovered. Thus, they were not included in further analysis. 


\section{Figure 2. Macroprudential authorities (level of development)}

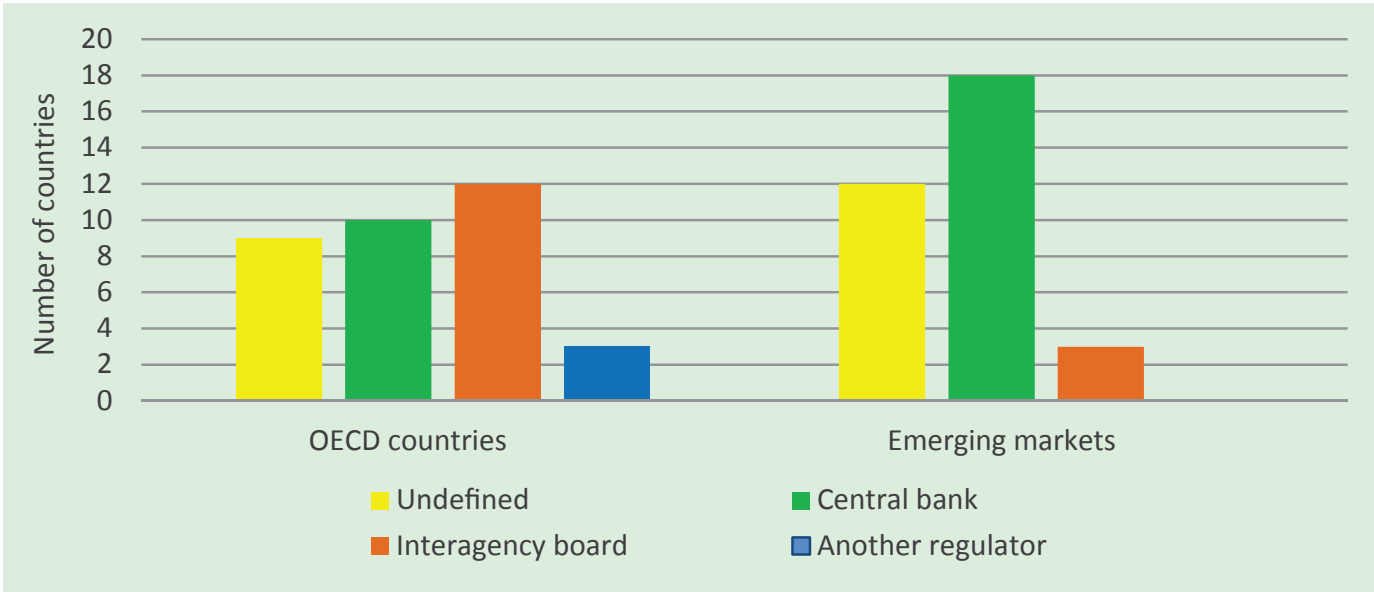

In emerging market economies (like Malaysia, Serbia, or Thailand), the most widespread approach is giving the MPM to a central bank, while designating an interagency board as a macroprudential authority is relatively less common.

There is a growing trend of putting MPMs into law. This is especially typical for the EU. In 29 out of 30 European countries covered with officially designated macroprudential authorities, the MPM is outlined in laws. In many cases, amendments are made to legal acts already in force, especially if a central bank is vested with the MPM. At the same time, there is a widening practice in recent years of the adoption of new dedicated "macroprudential laws." This is mostly the case where a board became the macroprudential authority, ${ }^{4}$ e.g. in Croatia, Germany, Slovenia (all laws in 2013), Iceland (2014), Luxembourg, and Poland (2015).

Another interesting aspect is a dependence of the MPM's distribution on the role of the central bank in the area of supervision and regulation of financial sector.

The results of the study suggest that the wider the mandate a central bank has (especially for supervision), the more likely it is given the MPM (see Table 1). Such distribution is in line with recommendations of the ESRB and the IMF. On all occasions when a central bank is a megaregulator, ${ }^{5}$ it is also a macroprudential authority. However, in Estonia and Lithuania, central banks received MPMs in spite of having no mandate even for banking sector supervision. One of the reasons behind this phenomenon is probably the experience gained by central banks in the area financial sector analysis as well as the institutional capacity traditionally associated with them.

It is also interesting to compare the national approaches to MPM distribution and the framework of financial stability boards.

\section{Table 1. Correlation between the MPM and the central bank's mandate for supervision}

\begin{tabular}{|c|c|c|c|c|}
\hline & & \multicolumn{3}{|c|}{ Central bank's mandate for financial sector regulation } \\
\hline & & none & (partial) banking regulator & megaregulator \\
\hline \multirow{6}{*}{ 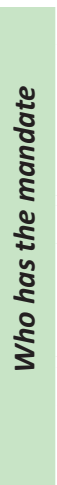 } & & 2 & 16 & 10 \\
\hline & $\begin{array}{l}\text { central bank } \\
\text { (28) }\end{array}$ & Estonia, Latvia & $\begin{array}{c}\text { Albania, Belgium, Cyprus, Greece*, Indo- } \\
\text { nesia, Ireland, Malta, Malaysia, Mongolia, } \\
\text { Nigeria, New Zealand, Portugal, Qatar, SAR, } \\
\text { Thailand, the UK* }\end{array}$ & $\begin{array}{c}\text { Armenia, Czech Republic, } \\
\text { Georgia, Hungary, Kazakhstan, } \\
\text { Lithuania, Oman, Serbia, Singa- } \\
\text { pore, Slovakia }\end{array}$ \\
\hline & \multirow[b]{2}{*}{$\begin{array}{l}\text { interagency } \\
\text { board (15) }\end{array}$} & 6 & 9 & 0 \\
\hline & & $\begin{array}{l}\text { Austria, Denmark, } \\
\text { Germany, Iceland, Lux- } \\
\text { embourg, Poland }\end{array}$ & $\begin{array}{l}\text { Bulgaria, Chile, Croatia, France*, the } \\
\text { Netherlands, Slovenia, Turkey, Uruguay, USA }\end{array}$ & - \\
\hline & \multirow{2}{*}{$\begin{array}{l}\text { other } \\
\text { regulators (3) }\end{array}$} & 2 & 1 & 0 \\
\hline & & $\begin{array}{l}\text { Sweden (FSA), } \\
\text { Finland (FSA) }\end{array}$ & Norway (Ministry of Finance) & - \\
\hline
\end{tabular}

\footnotetext{
${ }^{4}$ In most cases when an MPM was given to a central bank, the amendments are made to a current law on central bank

${ }^{5}$ Responsible for regulation of the entire financial system, not only the banking sector.
} 
Significantly, most of the countries studied have some interagency financial stability boards (councils, committees) or at least there exists some sort of memorandum on cooperation between financial sector regulators (in states where a central bank is also a megaregulator, the role of interagency boards is often taken over by internal financial stability committees) (see Table 2). As a rule in developed economies (OECD countries), interagency boards (if there any) are chaired by a representative of the government (by the Minister of Finance in most cases). At the same time, special rights and prerogatives of a central bank are protected within such boards (e.g., a veto right or the exclusive right to initiate application of macroprudential instruments in Germany). In all instances, central banks supply information and analytical support to the boards.

\section{Table 2. Who chairs interagency boards?}

\begin{tabular}{|c|c|c|c|c|c|}
\hline & $\begin{array}{c}\text { no interagency FS } \\
\text { board (14) }\end{array}$ & $\begin{array}{c}\text { central bank chairs } \\
\text { interagency FS board (21) }\end{array}$ & $\begin{array}{l}\text { FSA chairs } \\
\text { interagency } \\
\text { FS board (1) }\end{array}$ & $\begin{array}{l}\text { government chairs in- } \\
\text { teragency FS board (24) }\end{array}$ & $\begin{array}{c}\text { rotating } \\
\text { chairmanship } \\
\text { (6) }\end{array}$ \\
\hline & 6 & 5 & 0 & 1 & 0 \\
\hline \multirow[t]{2}{*}{$\begin{array}{l}\text { central bank - } \\
\text { megaregulator } \\
\text { (13) }\end{array}$} & $\begin{array}{l}\text { Armenia, Bahrain, } \\
\text { Czech Republic, } \\
\text { Georgia, Lithuania, } \\
\text { Singapore }\end{array}$ & $\begin{array}{l}\text { Belarus, Hungary, Ka- } \\
\text { zakhstan, Oman, Serbia }\end{array}$ & - & Russia & - \\
\hline & 6 & 14 & 0 & 15 & 4 \\
\hline \multirow[t]{2}{*}{$\begin{array}{l}\text { central bank - } \\
\text { banking } \\
\text { regulator (39) }\end{array}$} & $\begin{array}{l}\text { Belgium, Ireland, } \\
\text { Israel, Saudi Arabia, } \\
\text { UAE, UK }\end{array}$ & $\begin{array}{c}\text { Australia, Croatia, } \\
\text { Cyprus, Malaysia, Malta, } \\
\text { Nigeria, Netherlands, Phil- } \\
\text { ippines, Portugal, Qatar, } \\
\text { Romania, SAR, Slovenia, } \\
\text { Thailand }\end{array}$ & - & $\begin{array}{c}\text { Albania, Argentina, } \\
\text { Bulgaria, Chile, France, } \\
\text { Greece, Hong Kong, India, } \\
\text { Italy, Korea, Norway, Spain, } \\
\text { Turkey, Uruguay, USA }\end{array}$ & $\begin{array}{c}\text { Brazil, } \\
\text { Indonesia*, } \\
\text { Mongolia, New } \\
\text { Zealand }\end{array}$ \\
\hline & 2 & 2 & 1 & 8 & 2 \\
\hline $\begin{array}{c}\text { central bank } \\
\text { w/o supervision } \\
\text { mandate (15) }\end{array}$ & $\begin{array}{l}\text { Japan, Switzer- } \\
\text { land }\end{array}$ & Latvia, Denmark** & Austria & $\begin{array}{c}\text { Canada**, China, } \\
\text { Estonia, Germany, Iceland, } \\
\text { Luxembourg**, Mexico, } \\
\text { Sweden }\end{array}$ & $\begin{array}{l}\text { Poland, } \\
\text { Finland }\end{array}$ \\
\hline
\end{tabular}

In emerging market economies, the prevailing trend is that a central bank representative chairs the board (committee or council). Rotation of chairpersons is a rare practice in both groups of countries (see Figure 3 and 4).

\section{Figure 3. Who chairs interagency FS board, developed markets (OECD countries)}

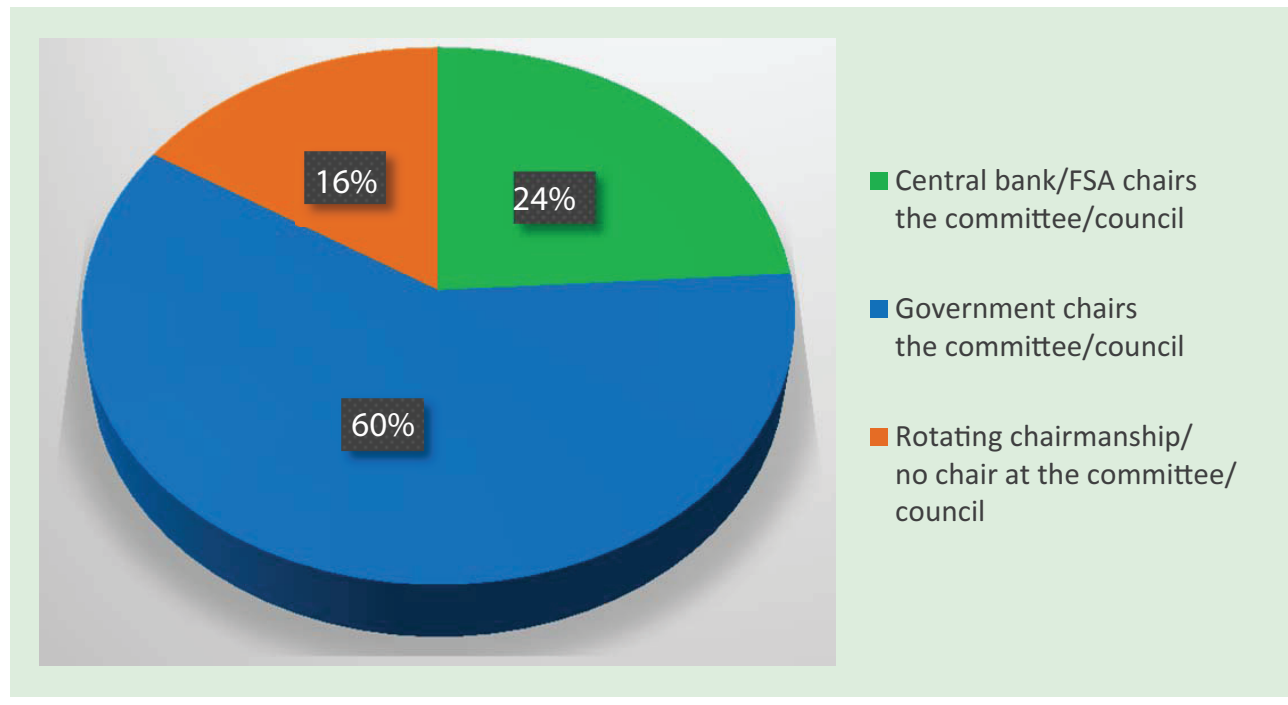

Note: Austria's case (FSA as a chair) is put into the "central bank/FSA chairs the committee/council" category. Cases where the chair changes depending on the economic cycle (crisis or "normal times" - Polish example) is categorized as "rotating chairmanship...". 


\section{Figure 4. Who chairs interagency FS board, emerging markets}

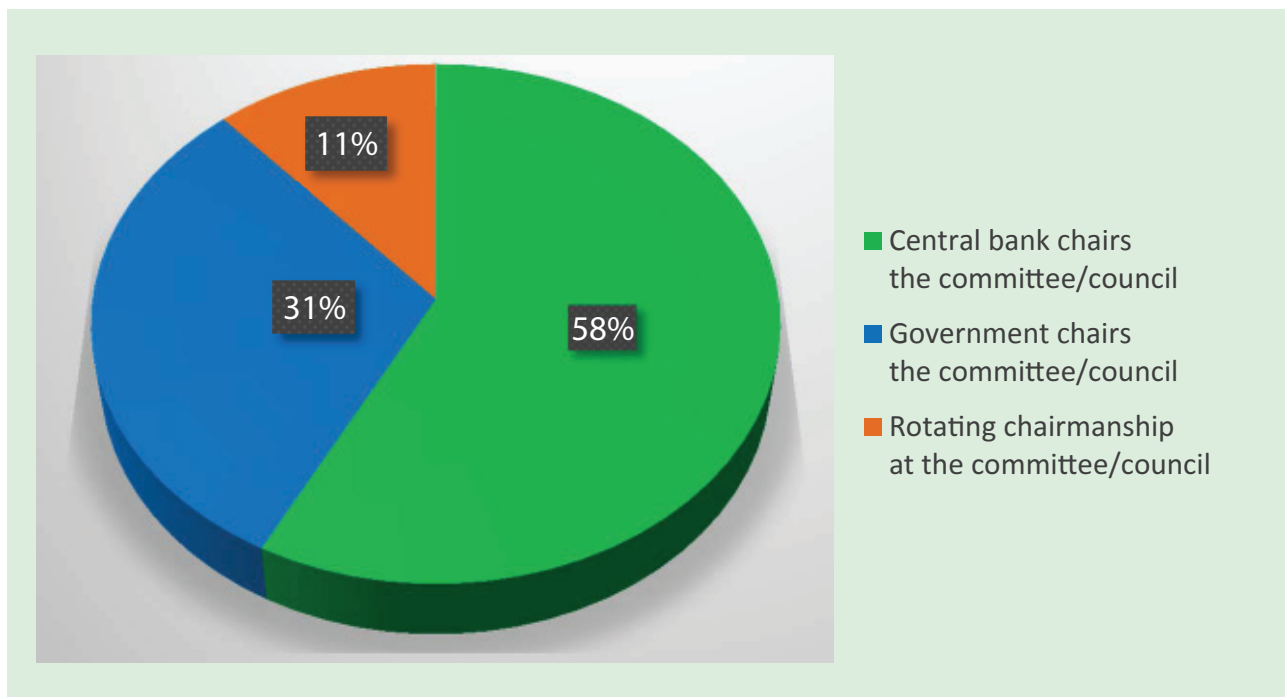

However, the existence of an interagency financial stability board (observed in 53 countries) was not a decisive factor for the process of designation of a macroprudential authority (see Figure 5). Thus, although establishment of a financial stability boards is a widespread practice, their role within macroprudential framework varies depending on national conditions.

\section{Figure 5. Macroprudential mandates in countries with an interagency financial stability board (53)}

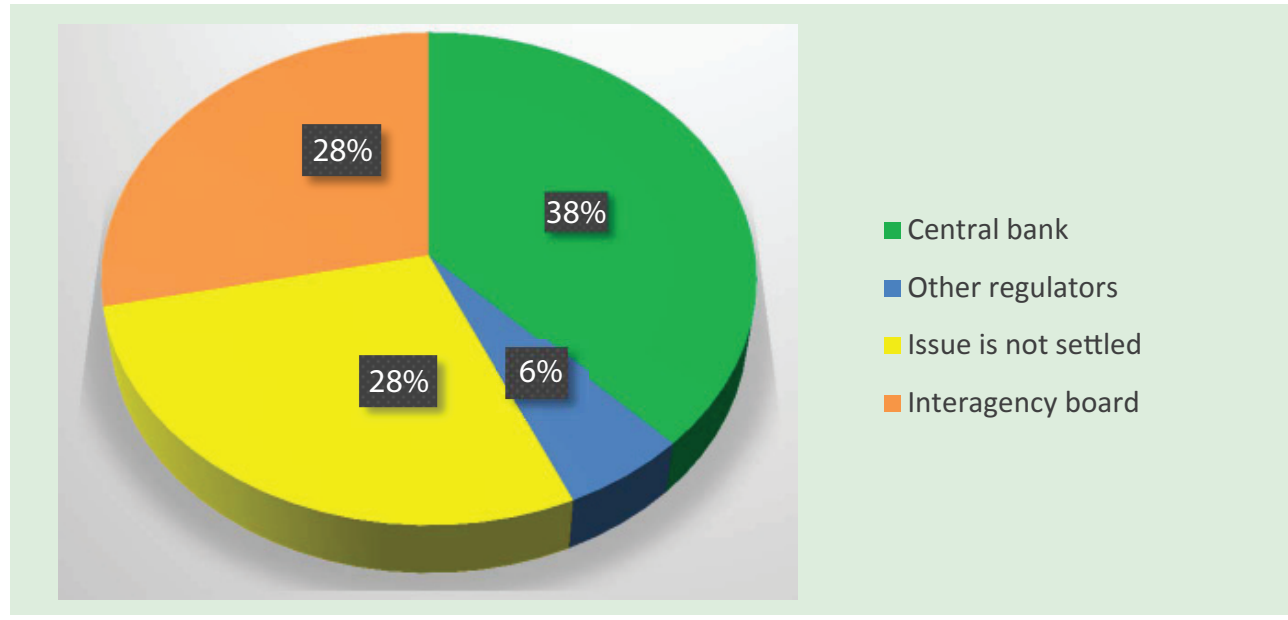

Another matter closely related to MPM is the application of macroprudential instruments ${ }^{6}$ (see Figure 6 ). In most of the reviewed cases, central banks are the authorities that apply macroprudential instruments - in 40 out of 67 countries (both in countries where central banks have an MPM and in economies where the situation is not yet formally settled). There are also numerous cases of application of macroprudential instruments by FSAs. However, a division of responsibilities for financial stability was observed between regulators in many countries. The division takes the shape of either allotting macroprudential instruments to mandates of different regulators or the establishment of multi-stage procedures that involves both the initiating institution and a collective (interagency) financial stability board.

\footnotetext{
${ }^{6}$ In order to ensure compatibility of comparisons, the study concentrates on Basel III macroprudential instruments.
} 


\section{Figure 6. Who applies macroprudential instruments}

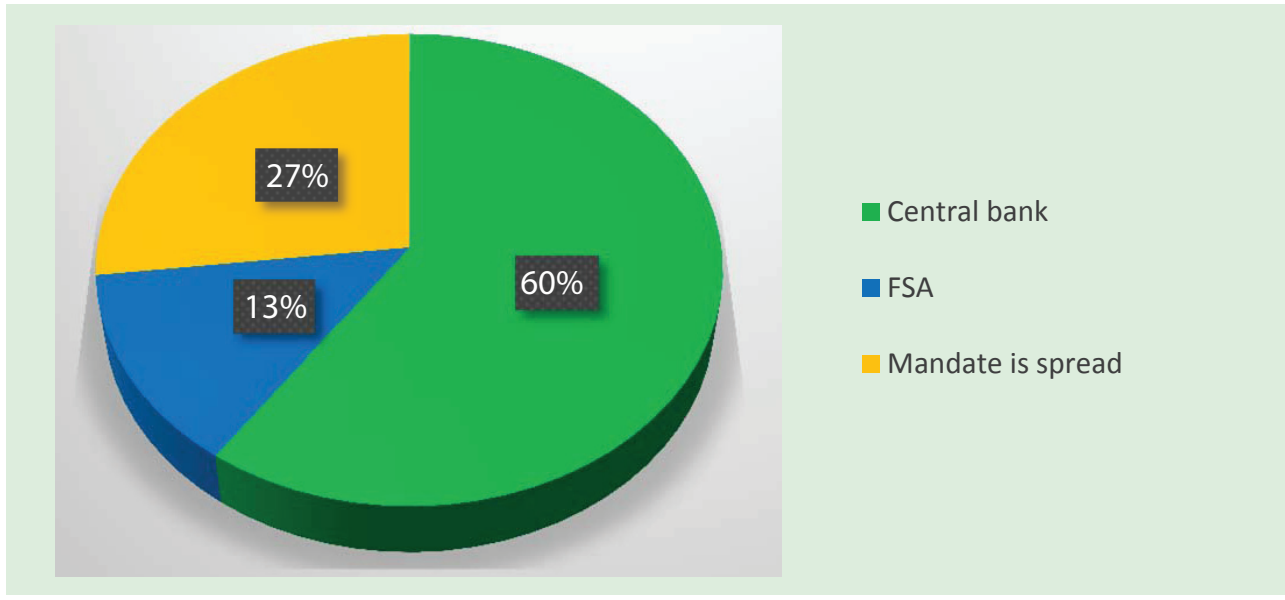

There are several practical ways of incorporating the mandate for application of macroprudential instruments into the legal system: either through a dedicated law on macroprudential supervision, or a separate law on banking (financial) supervision, or via a (internal) by-law by the regulator. The EU member states stand out, however, as they are obliged to implement EU directives, as well as mechanisms stipulated by EU regulations, into national legislation. Thus, the mandates to apply macroprudential instruments have to be put into law.

In some cases, the situation with rights to apply macroprudential instruments is rather intricate. A new Polish law presents an interesting example of the division of macroprudential competences, including the rights to apply macroprudential instruments (see Figure 7). The law divides the powers to initiate, to approve, and to apply the instruments between regulators at different levels. A regulator may initiate application of a tool within its competence as stipulated by law and submit its proposal to the Financial Stability Committee. If the decision of the Committee is positive, the regulator applies the instrument. On one hand, this framework establishes a system of checks and balances between regulators and promotes joint balanced decisions. On the other hand, the system may prove to be too rigid and complex to ensure timely solutions for crisis situations.

\section{Figure 7. Macroprudential framework in Poland}

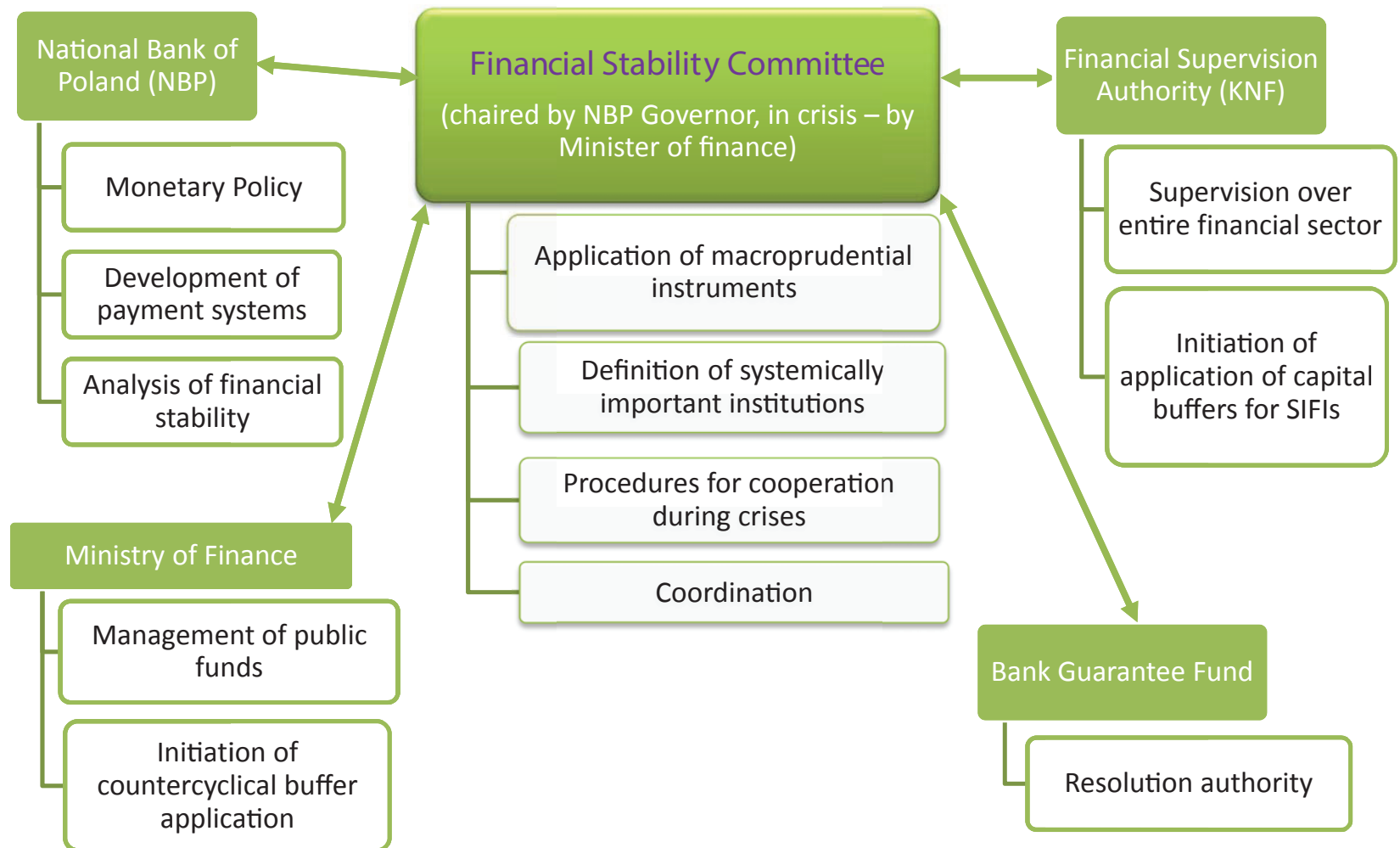


At the same time, initiation and making decisions on application of macroprudential instruments is concentrated within central banks in the Czech Republic and the Slovak Republic. This focuses responsibility on one regulator (thus making the entire framework more transparent) and promotes more expedient decision-making.

Therefore, in spite of regional and national economic and political differences between the countries, the factors taken into account while making a policy decision on the designation of macroprudential authority normally are the national model of the financial system, the real scope of powers, and level of independence and institutional capacity of financial regulators. The fact of whether or not the country has an interagency financial stability board in many cases was not a decisive factor for designation of an authority with an MPM.

\section{SITUATION IN UKRAINE: INSTITUTIONAL FRAMEWORK IS ESTABLISHED. WHAT'S NEXT?}

As of today, the NBU de-facto performs the mandate for ensuring financial stability in Ukraine.

Part 3 of Article 6 of the Law of Ukraine On the National Bank of Ukraine stipulates in particular that, "The National Bank shall promote, within the limits of its authority, financial stability, including stability of the banking system, without prejudice to the objective set forth in the second part of this article" (i.e., securing price stability). The wording was adopted only in 2015. Similar to most central banks, the NBU proceeds with a priority of achieving and securing price stability, but it also pays close attention to the state of the financial system in general and to analysis and mitigation of risks that undermine its resilience. Therefore, the function of analysis of financial stability is mentioned now in articles 7 and 57 of the current Law On the National Bank of Ukraine.

Another body with a mandate in the area of financial stability is the Financial Stability Council (the Council hereinafter). It was established by Presidential Decree No. 170 of 24 March 2015. The Council comprises heads of the NBU, the Ministry of Finance, the Deposit Guarantee Fund, and two financial market regulators (National Commission for Securities and Stock Market and National Commission for State Regulation of Financial Services Markets). The choice of members is logical. First, the members have influence on virtually all key processes in the financial system. Second, the absence of outsiders promotes in-depth professional discussions, minimizes political interest towards the work of the body, and prevents leaks of sensitive information.

In line with best international practices, the Council considers only systemic risks. These risks threaten to destabilize the functioning of the entire financial sector rather than to undermine the work of individual institutions (regardless of their size). Typical examples of systemic risks include sharp increases in public debt, substantial drops of prices in global commodity markets, and growing "bubbles" on some markets.

It should be noted that the Council is a platform for professional discussion, not a decision-making center or public authority. ${ }^{7}$ Any (even the slightest) pressure from politicians would only impede an impartial exchange. The Council does not compromise mandates of its member-institutions and does not interfere with activities of other public authorities. The Council may only recommend certain measures based on its deliberations. The addressee of a recommendation has to either comply or explain its reasons behind its failure to comply, which is in line with the common European "act or explain" principle.

Other regulators (National Commission for Securities and Stock Market and National Commission for State Regulation of Financial Services Markets) have no legal mandate for promoting financial stability (not to mention an MPM) despite their stake in financial stability and certain powers that can influence it. Thus, their formal influence over financial stability is limited to participation in the Council.

The Council has held seven meetings so far. At these meetings, the Council traditionally reviewed systemic risks to the stability of the financial system and economy in general and discussed a few acute issues that required coordination of regulators' efforts. No formal recommendations were developed up until now, mostly because the interagency board continues to study international experiences and makes efforts to construct the "proper format." However, frank and substantial exchanges in the Council format facilitated certain decisions with material results. In particular: the guidelines for transformation of state-

\footnotetext{
${ }^{7}$ The power of the Council to make decisions in the presence of signs of unstable financial conditions of the banking system or the emergence of circumstances threatening the resilience of Ukraine's banking/financial system can be considered as a certain exception from the general rule. Such a decision gives the NBU authority to set temporary special requirements in regulation and supervision over banks and other entities subject to NBU supervision (Article 71 of the Law of Ukraine On the National Bank of Ukraine). However, taking into account that this item extends the NBU's authority and does not limit it, one can argue that this regulation is in line with the mentioned principle.
} 
owned banks were refined; the Deposit Guarantee Fund received additional funding of UAH 21.5 billion from the Government in late 2015 to cover pay-outs to depositors at the banks that went bankrupt; and key prerequisites were ensured allowing the NBU to launch a new monetary regime - inflation targeting.

At the moment, given current tasks, the absence of a legally affirmed MPM in Ukraine should not be viewed as a serious hold-back for financial sector supervision (including macroprudential supervision). The NBU already has the powers necessary to analyze and monitor financial stability and to apply prudential tools for macroprudential purposes. However, the efficiency of the NBU's financial stability policy is limited if risks emerge beyond the banking sector's perimeter. In such situations, the NBU has to rely on the institutional capacity of other financial regulators and efficient cooperation with them. The steps for consolidation of financial supervision planned at the national level will only partially relax these limitations.

Given Ukraine's European aspirations (and thus ESRB recommendations), the global trends in financial sector development, as well as plans for further development of a macroprudential toolkit, defining a legally affirmed MPM becomes the most desirable scenario.

\section{CONCLUSIONS AND RECOMMENDATIONS}

While defining the MPM in Ukraine, the following factors should be considered:

- The Ukrainian financial sector is bank-centric (dominated by banks). The share of the banking system in total financial system assets was around $80 \%$ in 2015.

- The NBU now regulates and supervises the banking sector and ensures the oversight of payment systems. The supervisory mandate of the NBU will be further expanded once the law on consolidation of financial supervision ${ }^{8}$ is adopted and the functions of National Commission for State Regulation of Financial Services Markets are split.

- The NBU accumulated the most extensive experience of financial stability analysis (over the entire financial sector) among Ukrainian regulators. It possesses the necessary knowledge and skills on processes in the financial sector, macro- and microdata, and adequate instruments, including a modeling toolkit and organizational capacity.

- The NBU is de jure and de facto Ukraine's most independent financial sector regulator.

- The Financial Stability Council works in Ukraine for the second year. It has a mandate for both crisis prevention and crisis management. The Council members possess necessary information on all segments of the financial system and are directly responsible for their regulation. Organizational and analytical support for the Council is provided by the secretariat working within the Financial Stability Department of the NBU.

Upon receiving a mandate for regulation of a wider range of financial institutions (which should be transferred from the National Commission for State Regulation of Financial Services Markets), the NBU will approach the status of a financial megaregulator. Given that and taking into account the aforementioned arguments and with regard to international practices, we believe that it is necessary to formally (legally) vest the MPM in the NBU. This step will also be in line with the ESRB recommendations. For this, it will suffice to make amendments to the existing Law On the National Bank of Ukraine.

At the same time, the Financial Stability Council shall remain an important platform for cooperation between financial regulators. Moreover, given the consolidation of financial supervision and the need for enhanced coordination of regulators' actions, there might be an emerging call for extension of the Council's mandate and functions. In particular, this may relate to coordinated control measures to mitigate cross-sectoral systemic risks. 


\section{References}

- Act of the Republic of Croatia (2013). Act on the Financial Stability Council. OG 159/2013.

- Act of the Republic of Poland (2015). Ustawa o nadzorze makroostrożnościowym nad systemem finansowym i zarządzaniu kryzysowym w systemie finansowym. Uchwalono na pos. nr 98 dnia 05-08-2015, Dz.U. poz. 1513.

- Act of the Republic of Slovenia. Zakon o makrobonitetnem nadzoru finančnega Sistema. Uradni list RS, št. 100/13.

- Act on Monitoring Financial Stability (Financial Stability Act) - Gesetz zur Überwachung der Finanzstabilität (Finanzstabilitätsgesetz) in the wording of the announcement of 28 November 2012 (Federal Law Gazette I, page 2369) as last amended by Article 2 paragraph 36 of the Act of 1 April 2015 (Federal Law Gazette I, p. 434).

- Act on the Financial Stability Council (2014). Iceland, No. 66, dated 28 May 2014.

- Arvai Z., Prasad A., Katayama K. (2014). Macroprudential Policy in the GCC Countries. IMF Discussion note, No. SDN/14-01. https://doi.org/10.5089/9781484334430.006

- Bank of Slovenia. Macroprudential Policy for the Banking Sector - Strategic Framework.

- Basel Committee on Banking Supervision (2012). Core Principles for Effective Banking Supervision.

- Bank for International Settlements (2011). Central bank governance and financial stability. A report by a Study Group chaired by Stefan Ingves.

- Borio C., Drehmann M. (2009). Towards an operational framework for financial stability: fuzzy measurement and its consequences. Working Paper, No. 284, BIS.

- Borio C., Shim I. (2007). What can (macro-) prudential policy do to support monetary policy? Working Papers, No. 242, BIS.

- Bruno V., Shim I., Song Shin H. (2015). Comparative assessment of macroprudential policies. Working Papers, No. 502, BIS.

- Claessens S. (2014). An Overview of Macroprudential Policy Tools, Working Paper, No. 14-214, IMF.

- Committee on the Global Financial System (2010). Macroprudential instruments and frameworks: a stocktaking of issues and experiences. CGFS Papers, No. 38.

- Egawa E., Otani A., Sakiyama T. (2015). What Determines Institutional Arrangements for Macroprudential Policy? Discussion Paper Series, No. 2015-E-3, IMES.

- ESRB (2011). Recommendation on the macro-prudential mandate of national authorities. No. ESRB 2011-3.

- ESRB (2014). Recommendation on the macro-prudential mandate of national authorities. Follow-up Report - Overall assessment, No. ESRB 2011-3.

- ESRB (2014). The ESRB Handbook on Operationalising Macro-prudential Policy in the Banking Sector.

- ESRB (2015). National competent or designated authorities for CRD IV/CRR instruments and current or future implementation of macroprudential instruments.

- G20 London Summit (2009). Declaration on Strengthening the Financial System.

- Goodhart C. (2011). The Macro-Prudential Authority: Powers, Scope and Accountability. OECD Journal: Financial Market Trends, Vol. 2011, No. 2.

- Gramegna P. (2015). Loi du 1er avril 2015 portant création d'un comité du risque systémique et modifiant la loi modifiée du 23 décembre 1998 relative au statut monétaire et à la Banque centrale du Luxembourg. Journal Officiel du GrandDuché de Luxembourg, No. 64, p. 1294.

- IMF (2011). Macroprudential Policy: An Organizing Framework, Monetary and Capital Markets Department, approved by José Vi-als.

- Jansen B., Bossu W., Arda A., Knight D., Tamez M., Kroytor O., Gianviti F., Hockett R. (2013). Implementing Macroprudential Policy - Selected Legal Issues, IMF. 
- Liebeg D., Posch M. (2011). Macroprudential Regulation and Supervision: From the Identification of Systemic Risks to Policy Measures. Finanzmarktstabilitätsbericht, Oesterreichische Nationalbank.

- Lim C.H., Krznar I., Lipinsky F., Otani A., Wu X. (2013). The Macroprudential Framework: Policy Responsiveness and Institutional Arrangements. Working Paper, No. 13-166, IMF.

- Lim C., Columba F., Costa A., Kongsamut P., Otani A., Saiyid M., Wezel T., Wu X. (2011). Macroprudential Policy: What Instruments and How to Use Them? Lessons from Country Experiences. Working Paper, No. 11-238, IMF.

- Masahiro K., Morgan P. (2012). Central Banking for Financial Stability in Asia. Policy Research Institute, Ministry of Finance of Japan, Public Policy Review, Vol. 8, No. 3.

- Nier E. (2009). Financial Stability Frameworks and the Role of Central Banks: Lessons From the Crisis, Working Paper, No. 09-70, IMF.

- Nier E., Osiński J. (2013). Key Aspects of Macroprudential Policy. IMF.

- Nier E., Osiński J. (2013). Key Aspects of Macroprudential Policy. Background Paper, IMF.

- Nier E., Osiński J., Jácome L.I., Madrid P. (2011). Institutional Models for Macroprudential Policy. Discussion note, No. SDN/11-18, IMF. https://doi.org/10.5089/9781463926533.006

- Nier E., Osiński J., Jácome L.I., Madrid P. (2011). Towards Effective Macroprudential Policy Frameworks: An Assessment of Stylized Institutional Models. Working Paper, No. 11-250, IMF. https://doi.org/10.5089/9781463923327.001

- Osiński J., Seal K., Hoogduin L. (2013). Macroprudential and Microprudential Policies: Toward Cohabitation. Discussion note, No. SDN 13-05, IMF.

- Ozge A., Olmstead-Rumsey J. (2015). How Effective are Macroprudential Policies? An Empirical Investigation. International Finance Discussion Papers, No. 1136.

- Salim M.D., Wu X. (2015). Experiences with Macroprudential Policy - Five Case Studies. Working Paper, No. 15-123, IMF.

- Schinasi G. (2006). Safeguarding Financial Stability: theory and practice. IMF, Washington, D.C.

- Vinals J. (2011). The Do's and Don'ts of Macroprudential Policy, European Commission and ECB Conference on Financial Integration and Stability. Brussels, 2 May 2011. 


\title{
Nonlinear Exchange Rate Pass-Through to Domestic Prices in Ukraine
}

\author{
Oleksandr Faryna \\ National Bank of Ukraine \\ National University of "Kyiv-Mohyla Academy"
}

\begin{abstract}
This paper aims to estimate the degree of exchange rate pass-through (ERPT) to domestic prices in Ukraine considering nonlinearities with respect to the size and direction of exchange rate movements. We use disaggregated consumer price data and employ a panel autoregressive distributed lag model (ARDL) including threshold parameters to account for nonlinearities in the ERPT mechanism. We then compute dynamic ERPT coefficients taking into account inflation and exchange rate persistence. Estimation results suggest that the pass-through effect to core consumer prices is higher from currency depreciation than in the case of appreciation. On the contrary, we find that raw food prices are much more sensitive to appreciations. We also find that price responsiveness to small, medium, and large exchange rate changes is nonlinear. In particular, we provide evidence that prices are sensitive to small and extremely large changes, but the pass-through effect is insignificant if exchange rate movements are moderate.
\end{abstract}

\section{JEL Codes: E31, E52, E58, F31}

Keywords: exchange rate pass-through, inflation, Ukraine, nonlinear ERPT, Autoregressive Distributed Lag Model

\section{INTRODUCTION}

Exchange rate pass-through (ERPT) is traditionally defined as the percentage change in the price of imported good in local currency resulting from a one percent change in the nominal exchange rate. ${ }^{1}$ The puzzle of incomplete ERPT to import prices has become a trending research topic in theoretical and empirical literature since the breakdown of the Bretton Woods system. Furthermore, its importance from the monetary policy perspective extended the focus of such interest to capture the effect of exchange rate movements to all domestic price indices. Understanding the mechanism of exchange rate shocks transmission into domestic inflation might be a useful instrument for inflation forecasting, thus allowing the monetary authority to react efficiently to such shocks and maintain price stability.

Given the particular importance of the ERPT mechanism for open economies in transition, the literature on exchange rate pass-through in Ukraine is scarce. To our knowledge, few studies provide empirical estimates of ERPT for Ukraine (see Table 1). Korhonen \& Wachtel (2005) study ERPT to consumer prices in CIS countries. Authors use the VAR approach and impulse response analysis and estimate ERPT to consumer prices in Ukraine at a level of 0.63-0.64. Compared to other CIS countries, results for Ukraine are relatively high. Following a similar approach, Beckmann \& Fidrmuc (2013) provide ERPT estimates for seven CIS countries and confirm results for a high pass-through in Ukraine. They extend their analysis to measure US dollar and Euro exchange rates pass-through separately and find that Ukrainian prices are much more sensitive to US dollar exchange rate changes (0.45) than to Euro (0.25). Novikova \& Volkov (2012) employ a VEC framework and find that ERPT to core inflation in Ukraine amounts to a level of 0.35-0.47. 


\section{Table 1. ERPT for Ukraine in empirical literature}
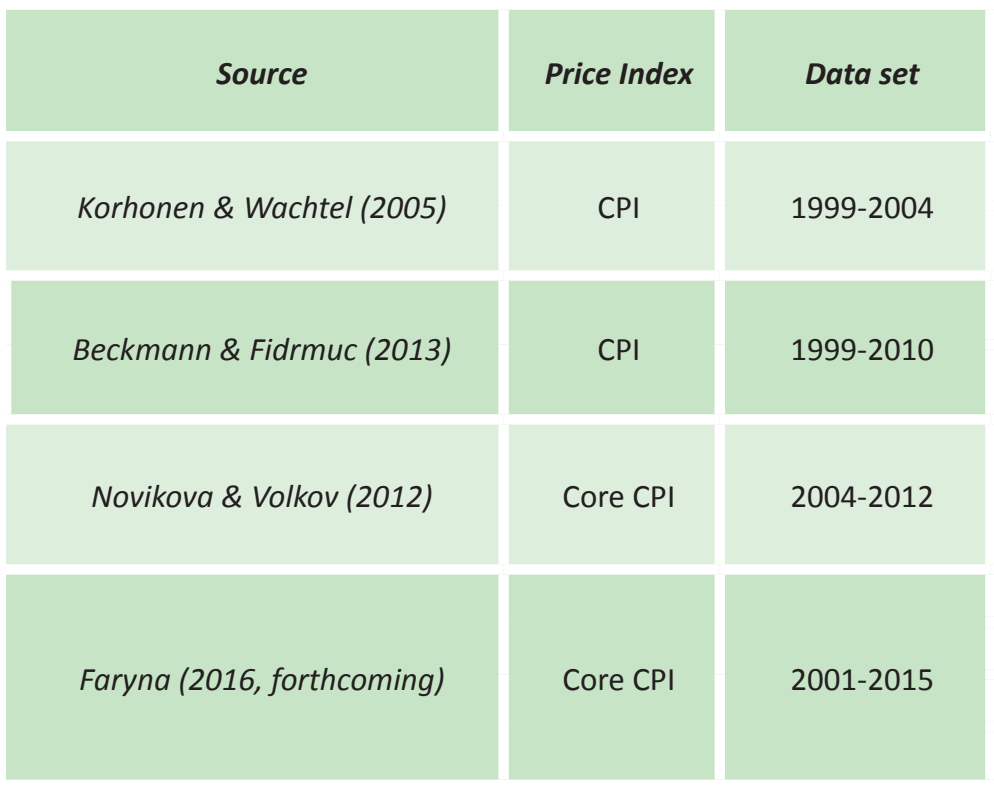

\begin{tabular}{|c|}
\hline Exchange Rate \\
\hline USD \\
\hline EUR \\
\hline USD \\
\hline EUR \\
\hline USD \\
\hline USD \\
\hline EUR \\
\hline NEER \\
\hline RUB \\
\hline
\end{tabular}

\begin{tabular}{|c|}
\hline Ukraine \\
\hline $0.63-0.64$ \\
\hline $0.24-0.28$ \\
\hline 0.45 \\
\hline 0.25 \\
\hline $0.35-0.47$ \\
\hline $0.40-0.42$ \\
\hline $0.20-0.21$ \\
\hline $0.27-0.28$ \\
\hline $0.09-0.10$ \\
\hline
\end{tabular}

Although empirical results are mixed, they all indicate a relatively high degree of exchange rate pass-through in Ukraine. However, all of these studies avoid, or include partially, analysis of ERPT asymmetry and nonlinearity. Therefore, in our paper we attempt to fill the gap in the literature and provide thorough evidence on the nonlinear exchange rate pass-through to consumer prices in Ukraine with respect to the size and direction of exchange rate changes. Following a well recognizable microfounded mark-up approach, we first employ a linear Autoregressive Distributed Lag Model (ARDL) and then extend the linear set-up by inclusion of nonlinear dummy parameters in order to capture asymmetries between appreciation and depreciation, as well as nonlinearities between small and large exchange rate changes. The degree of exchange rate pass through is then estimated using dynamic multiplier coefficients considering inflation and exchange rate persistence.

The rest of the paper proceeds as follows: a brief overview of the literature on ERPT and analytical framework of our analysis are presented in Sections 2 and 3 respectively; Section 4 provides an estimation approach and data description; estimation results can be found in Section 5; and then followed by conclusions in Section 6.

\section{BRIEF LITERATURE SURVEY}

In the following section, we draw on existing literature to discuss arguments on the nonlinear response of domestic prices to exchange rate fluctuations. We also review empirical evidence of ERPT asymmetry and nonlinearity across countries.

\section{A. Asymmetric pass-through from depreciation and appreciation}

The literature on ERPT asymmetry with respect to the direction of exchange rate changes generally consider a micro-founded "pricing to market" theory in explaining nonlinearities. Under this framework, the mark-up responsiveness from depreciation and appreciation has an opposite nature. More specifically, appreciation of an importing country's currency has a positive effect on a foreign exporter's mark-up and, thus, the absorption of exchange rate fluctuations (i.e., raising the mark-up and keeping constant prices expressed in an importing country's currency) is more desirable. In the case of depreciation of an importer's currency, a foreign exporter has an incentive to pass through exchange rate changes and raise prices in order to maintain stable profits.

However, as discussed in Pollard \& Coughlin (2004) and Marston (1990), assuming that foreign producers care about their market share, exporting firms are likely to pass-through exchange rate appreciation and decrease prices, expressed in the currency of the importer, in order to gain market share. Depreciation, in turn, will not be reflected in domestic prices given that foreign firms may never raise prices above the price of a substitute good in the importing country's market in order to hold on to market share. Hence, in a competitive environment, the response of domestic prices to exchange rate appreciation is higher than in cases of depreciation. 
On the contrary, in a climate of imperfect competition, a foreign producer has a high market share in the destination market and, thus, has substantial pricing power. Bussiere (2007) and Delatte \& Lopez-Villavicencio (2012) argue that the higher the market share, the lower the incentive of an exporter to absorb exchange rate depreciation (i.e., to keep constant prices in an importer's currency and decrease profits) and to pass-through appreciation (i.e., decrease prices and keep fixed profits). In this case, imperfect competition implies that prices are more sensitive to depreciations than to appreciations.

\section{B. Nonlinear pass-through from small and large exchange rate changes}

The effect form small and large exchange rate movements might also be nonlinear. Pollard \& Coughlin (2004) explain such nonlinearities by the presence of menu costs. Assuming that the change of the invoice price is costly for an exporting firm, ERPT from small and large changes may differ. In this case, the type of pricing strategy matters (i.e., local currency pricing vs. producer currency pricing). The invoice price changes if the exchange rate change is above a certain threshold level.

Under the producer currency pricing (PCP) strategy, the invoice price is set in the exporter's currency. A foreign firm may not adjust its invoice prices due to a small exchange rate change, which implies that prices expressed in an importer's currency will fully reflect exchange rate movements. In this case, ERPT is complete. However, in order to react on demand conditions and maintain a market share, exporters may absorb a part of the exchange rate pressure from large changes and adjust prices in their currency, thus reducing the degree of pass-through to prices in an importing country's currency.

On the contrary, under the local currency pricing (LCP) strategy, the invoice price is set in the importer's currency. In this case, import prices in domestic currency do not respond to small exchange rate changes. If the change is large, a foreign firm may adjust the price and increase the level of pass-through. Hence, LCP strategy implies that ERPT is higher when exchange rate changes are large than when they are small.

Different price-setting behaviors of exporting firms can be captured in empirical analysis by examining exchange rate passthrough to prices set in producer and local currencies separately. This requires a highly disaggregated and informative data range that is usually unavailable. In our analysis, we assume that producer currency pricing is prevalent in the case of Ukraine and, thus, following theoretical arguments, we can expect that aggregate domestic prices should be more sensitive to smaller rather than to larger exchange rate changes.

\section{Empirical evidence}

Theoretical literature is not straightforward in explaining the direction of ERPT asymmetry from depreciation and appreciation of different size. Moreover, empirical studies are not conclusive either. There is vast literature that confirms the presence of nonlinearities on the industry level and finds that the direction of asymmetry varies across industries.

Campa et al. (2005) use disaggregated data from EU countries and find that the extent to which import prices in manufacturing industries respond to appreciation episodes is higher than in the case of depreciation. In contrast, a symmetric response of prices for agriculture and commodity imports cannot be rejected. Pollard \& Coughlin (2004), in turn, provide ERPT estimates for 30 manufacturing industries and find that the degree of pass-through is positively related to the size of the exchange rate change. However, they also show that prices respond asymmetrically to appreciation and depreciation only in few industries and the direction of asymmetry varies. Bussiere (2007) also supports the presence of nonlinearities in ERPT. The author analyzes aggregate import prices in G7 counties and finds strong evidence of asymmetric ERPT, although the direction of asymmetries varies across countries. Nogueira \& Leon-Ledesma (2008) use aggregate consumer price data for six countries under inflation targeting regime and provide evidence that the magnitude of exchange rate variations is a driving factor of nonlinearities for some countries. Delatte \& López-Villavicencio (2012) also find that CPI response to exchange rate depreciation is higher than to appreciation in four developed countries.

To sum up, empirical literature provides strong evidence showing that nonlinearities in the pass-through mechanism cannot be neglected both for import prices, as well as for consumer prices. Given this fact, we attempt to relax the assumption of symmetric and linear ERPT to domestic prices in the case of Ukraine. 


\section{ANALYTICAL FRAMEWORK}

In this section, we briefly outline the analytical framework that we use to estimate exchange rate pass-through to consumer prices in Ukraine. We employ a standard micro-founded mark-up approach, commonly utilized in literature, as a starting point for our analysis. ${ }^{2}$ We then adapt it to estimate ERPT to consumer prices considering nonlinearities with respect to the size and direction of exchange rate changes.

Consider a single Foreign firm that sells a specific product to Home country and has pricing power in the importing country's market. The pricing behavior of a firm may be expressed by a simple profit-maximization problem:

$$
\max _{P^{H}} \pi=\frac{P^{H} Q}{E}-C(Q),
$$

where $\boldsymbol{\pi}$ is the exporting firm's profit in Foreign currency; $\boldsymbol{E}$ is the exchange rate of Home currency per unit of the exporting firm's currency; $\boldsymbol{P}^{H}$ is the price in Home currency; $C(Q)$ is the cost function in the Foreign currency, and $\boldsymbol{Q}$ is the quantity demanded.

The first-order condition of the equation (1) yields to the following form:

$$
P_{t}^{H}=E_{t} \mu_{t} C_{t}^{F}
$$

where $\boldsymbol{C}_{\boldsymbol{t}}^{\boldsymbol{F}}$ is the marginal cost of the exporting firm and $\boldsymbol{\mu}_{\boldsymbol{t}}$ is the mark-up over marginal cost. Equation (2) implies that the price of a product in Home currency may vary due to independent changes in the nominal exchange rate, Foreign firm's marginal cost, and mark-up, which, in turn, is assumed to depend on the demand conditions in the Home market $-\boldsymbol{Y}$.

In addition, we test in our analysis the hypothesis that mark-up responsiveness is asymmetric. More specifically, a foreign firm's decision whether to absorb or pass-through exchange rate depreciation may be different than in the case of appreciation. Incorporating these arguments, we consider the transition function $\boldsymbol{\gamma}(\boldsymbol{D})$ representing the nonlinear channel of ERPT with respect to the direction of exchange rate variations, where $D=\Delta e_{t-i}$ is the percentage change of the exchange rate. Thus, a foreign firm's mark-up can be expressed in the following functional form:

$$
\boldsymbol{\mu}_{t}=\boldsymbol{\mu}\left(\boldsymbol{Y}, \boldsymbol{E}^{\gamma(\boldsymbol{D})}\right) \text {. }
$$

Consequently, according to equation (2) and (3), a simple log-linear reduced-form ERPT equation would be ${ }^{3}$ :

$$
p_{t}^{H}=\alpha+\beta e_{t}+\gamma(D) e_{t}+\delta c_{t}^{F}+\rho y_{t}^{H}+\varepsilon_{t}
$$

Assuming that there is a threshold value of exchange rate change $D^{*}=0$, which divides extreme cases into regimes of appreciation and depreciation, the function $\gamma(D)$ may be further defined in the following way:

$$
\gamma(D)= \begin{cases}0, & \text { if } D>D^{*} \\ \varphi, & \text { otherwise }\end{cases}
$$

Inclusion of the transition function to our model enables the estimation of two different ERPT coefficients. From equation $(4)$, the joint ERPT coefficient is measured as $(\boldsymbol{B}+\boldsymbol{v}(\boldsymbol{D}))$. Hence, if the exchange rate depreciates and $\boldsymbol{D}>\boldsymbol{D}^{*}$, the degree of passthrough is $(\boldsymbol{B}+\boldsymbol{0}=\boldsymbol{B})$. However, in the case of appreciation, when $\boldsymbol{D} \leq \boldsymbol{D}^{*}$, ERPT is $(\boldsymbol{B}+\boldsymbol{\varphi}) .^{4}$

Following a similar approach, we consider nonlinearities in the pass-through mechanism with respect to the size of exchange rate movements. As described in section 2.B. of this paper, the presence of menu costs and different pricing strategies may affect a firm's decision on mark-up adjustment after small and large exchange rate movements. In this case, $D^{*}$ represents some threshold value below and above which exchange rate variations are assumed to be small and large, respectively. Hence, $\boldsymbol{B}$ measures the pass-through of a large exchange rate change, while $(\boldsymbol{b}+\boldsymbol{\varphi})$ measures the pass-through of a small change.

\footnotetext{
${ }^{2}$ For example, as in Goldberg \& Knetter (1997).

${ }^{3}$ Equation (4) is similar to one in Cheikh (2013) and Nogueira \& Leon-Ledesma (2007), where component $\gamma(D)$ was used to represent the business cycle and macroeconomic stability conditions in the destination country.

${ }^{4}$ The sign of $\phi$ indicates the direction of asymmetry, i.e., whether the transmission of exchange rate is higher or lower after depreciation and appreciation.
} 
The framework presented above describes the process of price adjustment from a microeconomic perspective and is usually used in literature to estimate exchange rate pass-through to import prices of tradables in specific industries. Nevertheless, we use it as a starting point and extend the model so that it is suitable to estimate ERPT to consumer prices. As argued in Bailliu \& Fujii (2004), a common assumption in empirical literature is that the aggregate price level and exchange rate follow nonstationary processes. Differentiation of variables expressed in logarithms results in the estimation of an inflation equation. In addition, following literature on inflation and ERPT to aggregate consumer prices, we also include inflation persistence to account for adaptive expectations. ${ }^{5}$ Furthermore, lagged values of other independent variables should be considered in order to capture the relationship in dynamics. Incorporating these arguments, equation (4) can be re-written as follows:

$$
\Delta p_{t}^{H}=\alpha+\sum_{i=1}^{n} \theta_{i} \Delta p_{t-i}^{H}+\sum_{i=0}^{k}\left(\beta_{i}+\gamma(D)\right) e_{t-i}+\sum_{i=0}^{q} \delta_{i} c_{t-i}^{F}+\sum_{i=0}^{r} \rho_{i} y_{t-i}^{H}+\varepsilon_{t}
$$

\section{ESTIMATION APPROACH AND DATA DESCRIPTION}

Considering a theoretical inflation equation (6) described in the previous section, we employ an ARDL model in our econometric set-up. A simple reduced-form $\operatorname{ARDL}(n, k)$ model can be presented as follows:

$$
Y_{t}=a_{0}+\sum_{i=1}^{n} a_{1, i} Y_{t-i}+\sum_{i=0}^{k} a_{2, i} X_{t-i}+\varepsilon_{t}
$$

where $\boldsymbol{Y}_{\boldsymbol{t}}$ is the dependent variable, $\boldsymbol{X}_{\boldsymbol{t}}$ represents an independent variable, $\boldsymbol{a}_{1, i}$ and $\boldsymbol{a}_{2, i}$ are parameters of the model, $\boldsymbol{a}_{\boldsymbol{0}}$ is a constant, and $\varepsilon_{t}$ is white noise.

An ARDL model can be easily estimated by ordinary list squares using lag selection criterions (e.g., Akaike, Shwarz, HannanQuinn information criteria). Interpretation of the coefficients in equation (7), where all variables are in first differences and in logarithms, is straightforward, indicating a percentage change of a dependent variable resulting from a $1 \%$ change of each regressor. In the case of ERPT estimation (i.e., when the dependent variable is inflation, and the independent is the exchange rate change), in order to account for the dynamic effect, we compute dynamic multiplier coefficients considering inflation persistence and past exchange rate movements.

Our analysis is based on the monthly frequency data and captures the period from January 2007 to April $2016 .{ }^{6}$ The data choice is based on the consideration of theoretical framework hypothesis, described in previous sections. Following a markup approach, we use disaggregated data of consumer prices (i.e., 258 indices) in Ukraine and estimate the nonlinear effect of exchange rate changes for the set of price groups separately, including:

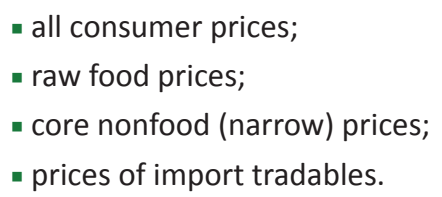

$$
\begin{aligned}
& \text { - core consumer prices; } \\
& \text { - core food prices; } \\
& \text { - prices of tradables; and }
\end{aligned}
$$

We use several price groups in our analysis in order to capture peculiarities of different consumer price indices. In particular, the group of "all consumer prices" includes prices of all goods and services. "Core consumer prices" excludes raw food prices, administratively regulated prices and services, and fuel prices. Moreover, following the analytical framework of our analysis, which aims to explain the pass-through effect to prices of goods, we also estimate the response of core food and nonfood prices excluding services. Finally, the pricing-to-market theory assumes that exporting firm's mark-up responsiveness may depend on demand conditions in the importing country and prices of domestically produced substitutes. Hence, we narrow the analysis to study the pass-through effect to prices of tradable goods. In addition, we also examine import tradables, which may be particularly sensitive to exchange rate movements. All price indices are normalized (December $2006=100$ ) and seasonally adjusted using an X-12 additive monthly seasonal adjustment method.

Korhonen \& Wachtel (2005) argue that the US dollar exchange rate is one of the most important relative prices in most CIS countries, including Ukraine. In addition, Coibion \& Gorodnichenko (2015) highlight the importance of the USD to UAH exchange rate for households' expectations. However, as a result of the exchange rate peg to the US dollar, a USD/UAH time

\footnotetext{
${ }^{5}$ Nogueira \& Miguel (2007) present an extension of the mark-up model for the case of consumer prices including inflation persistence and output gap to match Phillips curve.

${ }^{6}$ Data source: National Bank of Ukraine Statistics and State Statistics Service of Ukraine.
} 
series includes only several appreciation episodes and three stages of rapid depreciation in 2008, 2014, and 2015, which makes the estimation of nonlinearities problematic. On the contrary, the nominal effective exchange rate (NEER) is more volatile as it includes trade-weighted exchange rates of other countries. Thus, in our empirical analysis, the exchange rate variable is an inverted normalized NEER of domestic currency per unit of weighted foreign currencies (December 2006 = 100). A positive change in NEER indicates depreciation, while negative changes represent episodes of appreciation.

In order to account for demand conditions in an importing country, we use the Industrial Production Index gap (IPI), ${ }^{7}$ which is available on a monthly basis. Foreign producer costs, which, in turn, reflect supply conditions, are commonly expressed by inclusion of energy prices (e.g., oil prices), as in Koichi (2013), Delatte \& López-Villavicencio (2012), and McCarthy (2000, 2007). Thus, we use the Fuel Price Index (FPI) ${ }^{8}$ from the IMF Commodity Price Statistics in our analysis. All time series are in logarithms.

Following the above mentioned theoretical framework and estimation approach, we start with estimation of the baseline linear ARDL model to measure ERPT to consumer price indices. The lag length of each variable in the equation was selected using a "general to specific" approach and AIC statistics, resulting in the following ARDL specification:

$$
C P I_{t}=a_{0}+\sum_{i=1}^{3} a_{1, i} C P I_{t-i}+\sum_{i=0}^{3} a_{2, i} N E E R_{t-i}+\sum_{i=1}^{2} a_{3, i} I P I_{t-i}+\sum_{i=0}^{2} a_{4, i} F P I_{t-i}+\varepsilon_{t}
$$

We then use a baseline linear set-up model and add nonlinear elements to account for asymmetry with respect to direction and size of exchange rate movements (as in Pollard \& Coughlin (2004)). Firstly, we include two dummy variables $\boldsymbol{D}^{+}$and $\boldsymbol{D}^{-}$, which reflect periods of depreciation and appreciation, and estimate ERPT coefficients for different regimes separately. Then we repeat this procedure with dummy variables that reflect periods of small and large exchange rate changes. In order to test for a linearity hypothesis, we use the Wald-test imposing coefficient restrictions $\boldsymbol{\beta}_{D^{+}}=\boldsymbol{\beta}_{D^{*}}$.

Before discussing estimation results, an important issue on the choice of a transition variable and the threshold value should be raised. A transition variable is used to divide the exchange rate time series on several regimes (e.g., depreciation and appreciation, or small and large changes). Empirical literature on ERPT asymmetry (as in Pollard \& Coughlin (2004)) commonly use a percentage change of the exchange rate variable utilized in the regression equation as a transition variable. More specifically, within a monthly-based analysis, the sign of a monthly exchange rate change is used to divide a data set into regimes of depreciation and appreciation (i.e., $\Delta \boldsymbol{e}_{t-1}>\mathbf{0}$ and $\Delta \boldsymbol{e}_{t-1}<0$ ). However, one would argue that a transition variable should reflect exchange rate movements over some longer period in the past. In particular, the transition from one regime to another may not be instant. In our analysis, we choose a transition variable which covers all lagged values of the exchange rate in the inflation equation. In particular, the inclusion of three lags of exchange rate implies that the transition variable is the NEER quarterly percentage change ( $\Delta$ neer $\left.{ }_{t-3}\right)$.

Another important issue in the estimation of nonlinear ERPT is the choice of a threshold value. While for the direction of exchange rate movements a threshold value simply equals zero, a measurement of the size of exchange rate changes requires additional assumptions. Pollard \& Coughlin (2004) use an arbitrarily chosen threshold value of $3 \%$ in their analysis. In contrast, a set of empirical ERPT studies use Threshold Autoregressive models (TAR) or Smooth Transition Regressions (STR) in order to determine a threshold value endogenously. ${ }^{9}$

In order to measure asymmetries and nonlinearities in the ERPT mechanism for Ukraine with respect to the direction and size of exchange rate movements, we use several alternative threshold values (see Figure 2):

- Depreciation and appreciation periods are simply split by a threshold value which equals zero. This results in the division of the total number of observations into $61 \%$ of depreciation and $39 \%$ of appreciation episodes.

- To measure the magnitude of exchange rate variations, we first use a median of the absolute values of the quarterly NEER change, which approximately equals $3 \%$ (i.e., MED. $=0.0325$ ). Using the median allows for the division of the data set into two equal periods.

- Additionally, in the alternative model specification we use two standard deviations as a threshold value which approximately equals $16 \%$ (i.e., S.D. $=0.0794$ ). This helps to capture extremely large depreciation episodes in 2008, 2014 , and 2015. Although the fraction of extreme cases is $9 \%$, the panel dimension enables the estimation of the ERPT coefficient with a relatively low number of observations.

- Lastly, we use both threshold values of $3 \%$ and $16 \%$ to divide time series of the quarterly NEER change to periods of small changes (i.e., abs $\left(\Delta\right.$ neer $\left._{t-3}\right)<3 \%$ ), large changes (i.e., $a b s\left(\Delta\right.$ neer $\left.\left._{t-3}\right)>16 \%\right)$, and medium changes (i.e., $3 \%<a b s\left(\Delta\right.$ neer $\left.\left._{t-3}\right)<16 \%\right)$.

\footnotetext{
${ }^{7}$ The IPI gap is calculated by taking the difference of seasonally adjusted IPI and HP-filtered IPI in logarithms.

${ }^{8} \mathrm{FPI}$ includes Brent oil, natural gas, and coal prices.

${ }^{9}$ For example, Shintani (2009) uses a grid search approach to determine a threshold value.
} 
Figure 1. Transition variable (1 quarter NEER change) and threshold values
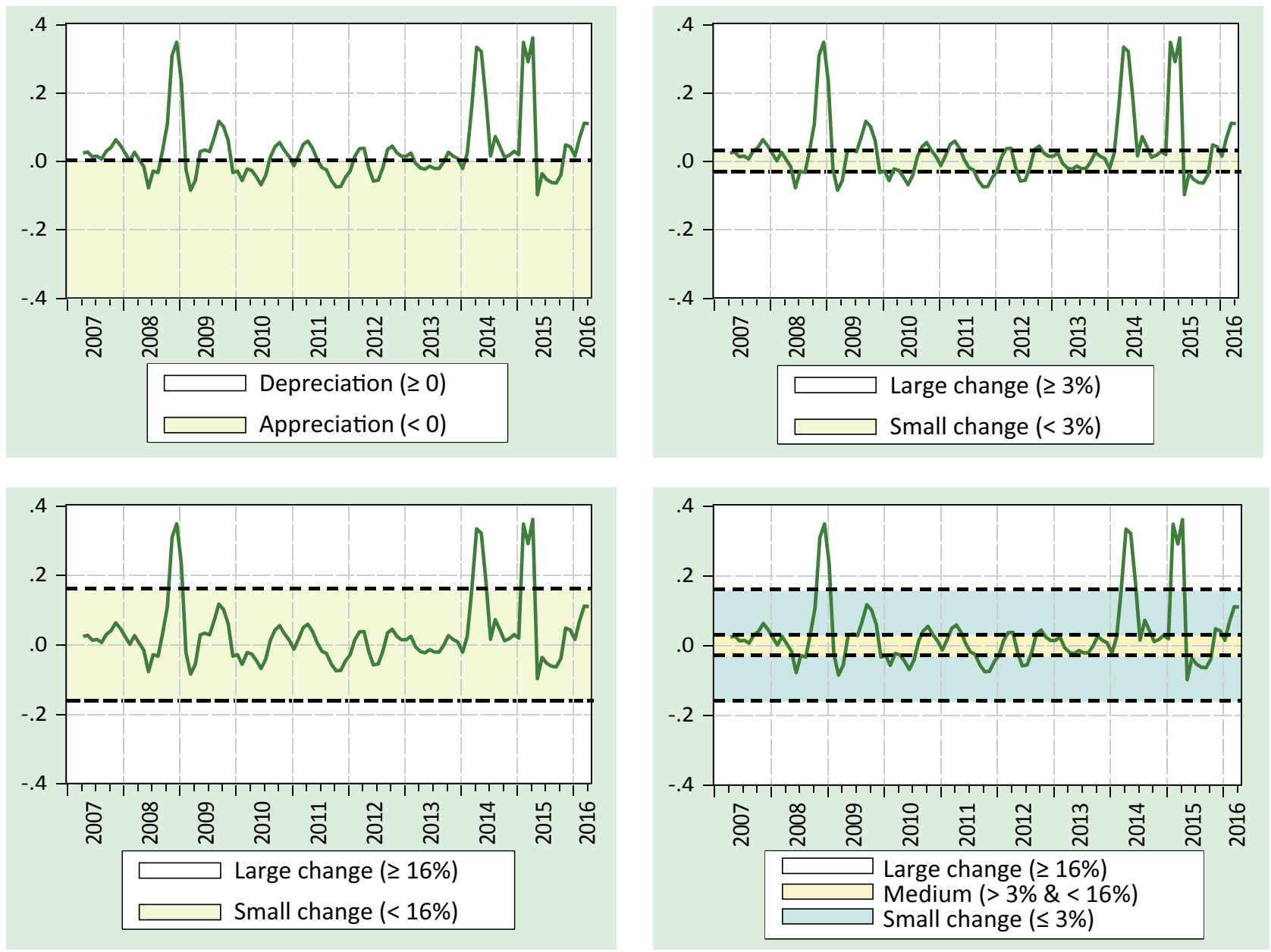

\section{ESTIMATION RESULTS}

Estimated coefficients were used to calculate the dynamic multiplier measuring the cumulative ERPT effect. Figure 2 shows the response of core consumer prices to a $1 \%$ NEER change. The left graph represents the effect on the price change (i.e., inflation) at each point in time, while right graph shows the accumulated response of prices.

Exchange rate pass-through for the group of all consumer prices is estimated at a level of 0.172 , which is in line with existing empirical studies for Ukraine. The response of core prices, prices of tradables, and import tradables is 0.181-0.189. For core food prices, the ERPT coefficient is somewhat higher -0.268 , while prices of core nonfood goods have the lowest pass-through of 0.154 . Interestingly, in the short-run, the degree of exchange rate pass-through ERPT for raw food prices rises to 0.24 , which is the highest compared to other price groups, and subsequently stabilizes at a level of 0.183. All ERPT coefficients are statistically significant at a $1 \%$ confidence level.

In the next step of our analysis, we estimate several nonlinear models considering different direction and size of exchange rate changes. Table 2 reports the summary results from a linear and four nonlinear ARDL specifications. 
Figure 2. Linear price responsiveness to $1 \%$ NEER change

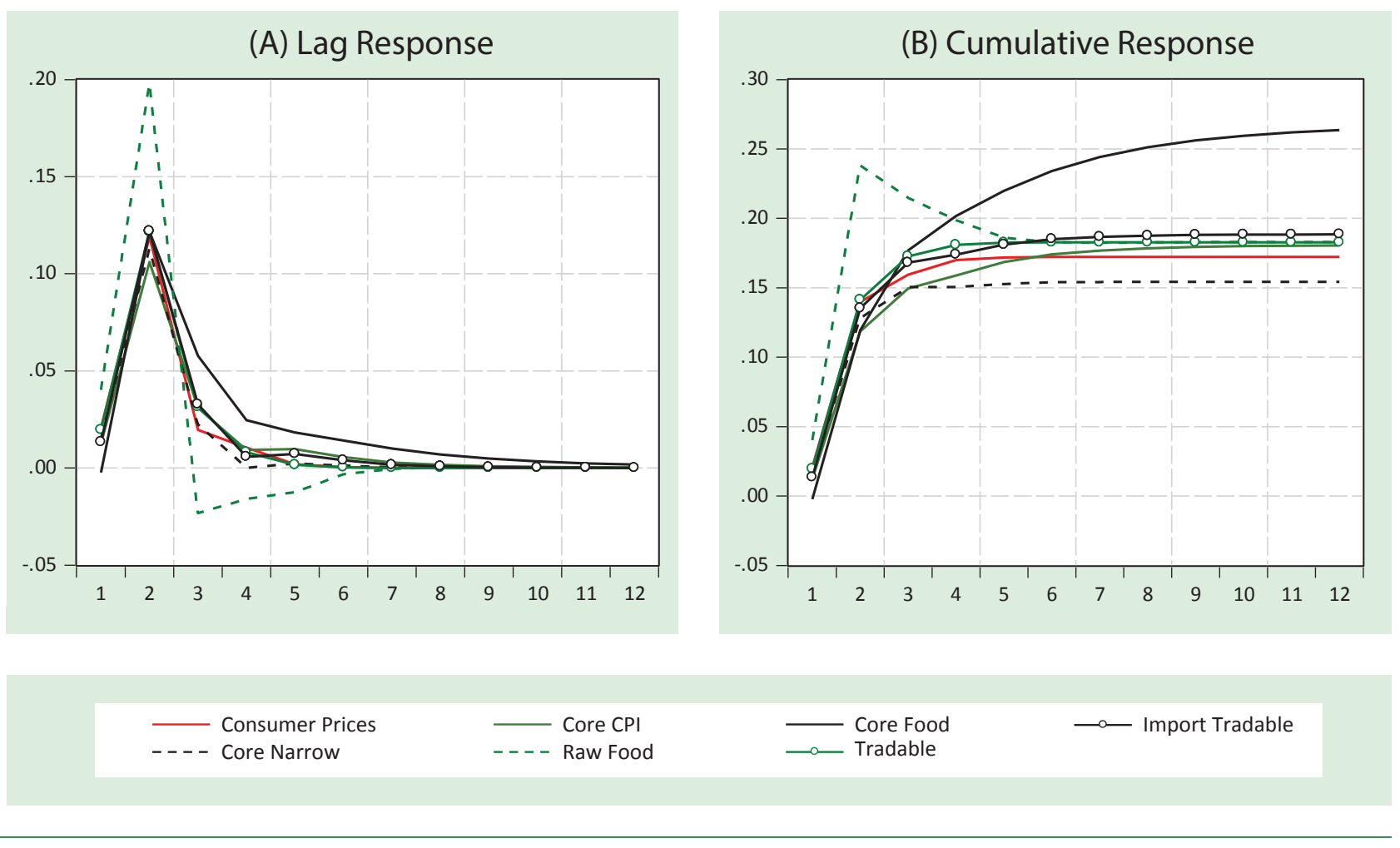

\section{A. Direction of exchange rate movements}

Figure 3 shows the cumulative price responsiveness to a one percent NEER depreciation and appreciation. Estimation results suggest that exchange rate pass-through is asymmetric with respect to the direction of NEER change for most of price groups. In particular, depreciation passes through to a larger extent than appreciation in the case of all consumer prices, core consumer prices, core nonfood prices, and prices of tradables and import tradables. These results are in line with the "pricingto-market" theory in a climate of imperfect competition. In this respect, foreign exporting firms have market power over importing countries' market and tend to adjust their mark-ups in response to appreciations, thus keeping fixed prices and rising profits. On the contrary, following depreciation of an importing country's currency, foreign producers have an incentive to raise prices and keep stable profits. Compared to the linear ARDL model, the degree of ERPT from depreciation is larger and varies from 0.221 for all consumer prices to 0.299 for the group of import tradables. Interestingly, ERPT from appreciations in some cases has a negative sign (i.e., currency appreciation increases domestic prices). As argued in Faryna (2016, forthcoming) this can be a result of sufficient cross-country spillovers in the ERPT mechanism. In particular, the pass-through effect from appreciation may be compensated by allowing for a higher order transmission channels between several countries.

In the case of raw food prices, ERPT asymmetry has an opposite direction. We find that a one percent NEER appreciation results in a 0.728 percent decline in prices of raw foods. Following theoretical assumptions, these results indicate much better competition conditions for such type of goods. Although the ERPT coefficient is statistically significant at a $99 \%$ confidence level, raw foods are usually sensitive to other external factors (e.g., crop yielding capacity) that are not considered in our analysis and may bias results. For the group of core food prices, the linearity hypothesis cannot be rejected, indicating no asymmetry in the ERPT mechanism.

\section{B. Size of exchange rate movements}

To study nonlinearities with respect to the magnitude of exchange rate movements, we first estimate the nonlinear ARDL model with a threshold value of $3 \%$. For most price groups, the linearity hypothesis is strongly rejected while results suggest that small NEER changes pass through to consumer prices to a larger extent than in the case of large changes. However, using a threshold value of a 16\% NEER change in the alternative NARDL specification results in the opposite direction of price responsiveness. In particular, we find that ERPT from extremely large NEER changes is larger. 
These results indicate that ERPT nonlinearities with respect to the size of exchange rate change may include more than one threshold value. Thus, we estimate the model allowing for small, medium, and large NEER changes. Figure 3 shows the cumulative price responsiveness considering three regimes. Results show that for most price groups, extremely large as well as small NEER changes have a considerable effect on consumer prices. Moreover, the linearity hypothesis cannot be rejected for core consumer prices, core food and nonfood prices, and prices of import tradables. On the contrary, medium NEER changes are statistically insignificant in all cases.

Considering theoretical arguments on ERPT nonlinearity, our results indicate the presence of menu costs, which implies that foreign exporting firms following a producer currency pricing strategy may not adjust their prices in response to small exchange rate changes. On the contrary, foreign producers may absorb the pressure from relatively larger exchange rate movements in their mark-ups in order to keep stable profits in the case of depreciation of the destination country's currency and in order to maintain or gain market share in the case of appreciation. Moreover, as argued in Nogueira \& Leon-Ledesma (2011), exchange rate pass-through can be higher in periods of financial or confidence crises, when firms have no incentive to absorb cost increases in their margins. This is in line with our estimates for Ukraine as extremely large exchange rate depreciation episodes where experienced under crisis conditions resulting in high ERPT.

\section{CONCLUDING REMARKS}

From the beginning of 2014, Ukraine has experienced a rapid depreciation of the hryvnia caused by dramatic shifts in the risk premium, adjustments to balance of payment mismatches, and unfavorable terms of trade, all of which aggravated macroeconomic turbulences and, eventually, resulted in peek inflation up to $60 \%$. Since 2015, the National Bank of Ukraine has declared a new direction for its monetary policy on inflation targeting (IT). In a climate of gradual economic stabilization and a floating exchange rate regime, the hryvnia depreciated by around $20 \%$. In contrast to past periods, it was mainly due to a drop in world commodity prices and imposed trade restrictions with Russia. In this case, the decrease of commodity prices had both a positive and negative effect on the aggregate price level. This, eventually, resulted in a relatively modest price adjustment.

Nevertheless, the adoption of IT and transition to a flexible exchange rate in a small open economy may be problematic if the risks associated with exchange rate volatility remain high. Hence, the ability of the NBU to attain its inflation targets requires a thorough understanding of the extent to which consumer prices respond to exchange rate movements.

Given the particular importance of exchange rate pass-through, literature that explores this issue in Ukraine is scarce. Although there are several comprehensive studies that provide empirical estimates for Ukraine, the time span of their analysis can be characterized by the period of the exchange rate peg to the US dollar, which was used to provide a nominal anchor for the economy. In this paper, we fill the gap in the literature by examining exchange rate pass-through issues in Ukraine. In particular, we attempt to answer the question of what extent consumer prices in Ukraine respond to depreciations and appreciations of different magnitude.

Following a standard mark-up approach, we find that in most price groups the pass-through effect from depreciation is higher than from appreciation, indicating weak competition in Ukraine. Additionally, we find that small changes have a considerable effect on price adjustments in Ukraine, while moderate changes are statistically insignificant. Given that foreign firms most often follow a producer currency pricing strategy while exporting goods to Ukraine, our results indicate the presence of menu costs for foreign producers. In addition, we find that the pass-through effect rises in the case of extremely large exchange rate depreciations. To sum up, the National Bank of Ukraine, while attaining its inflation targets, should be aware that consumer prices in Ukraine are sensitive to small and extremely large nominal effective exchange rate changes, while the pass-through effect is statistically insignificant in the case of moderate NEER fluctuations.

In addition to asymmetries and nonlinearities with respect to the direction and magnitude of exchange rate changes, empirical literature finds other sources of nonlinearities in the ERPT mechanism (e.g., inflation environment, business cycles, exchange rate volatility). Hence, studying these issues for Ukraine may be the subject of further research 
Table 2. Estimated exchange rate pass-through coefficients

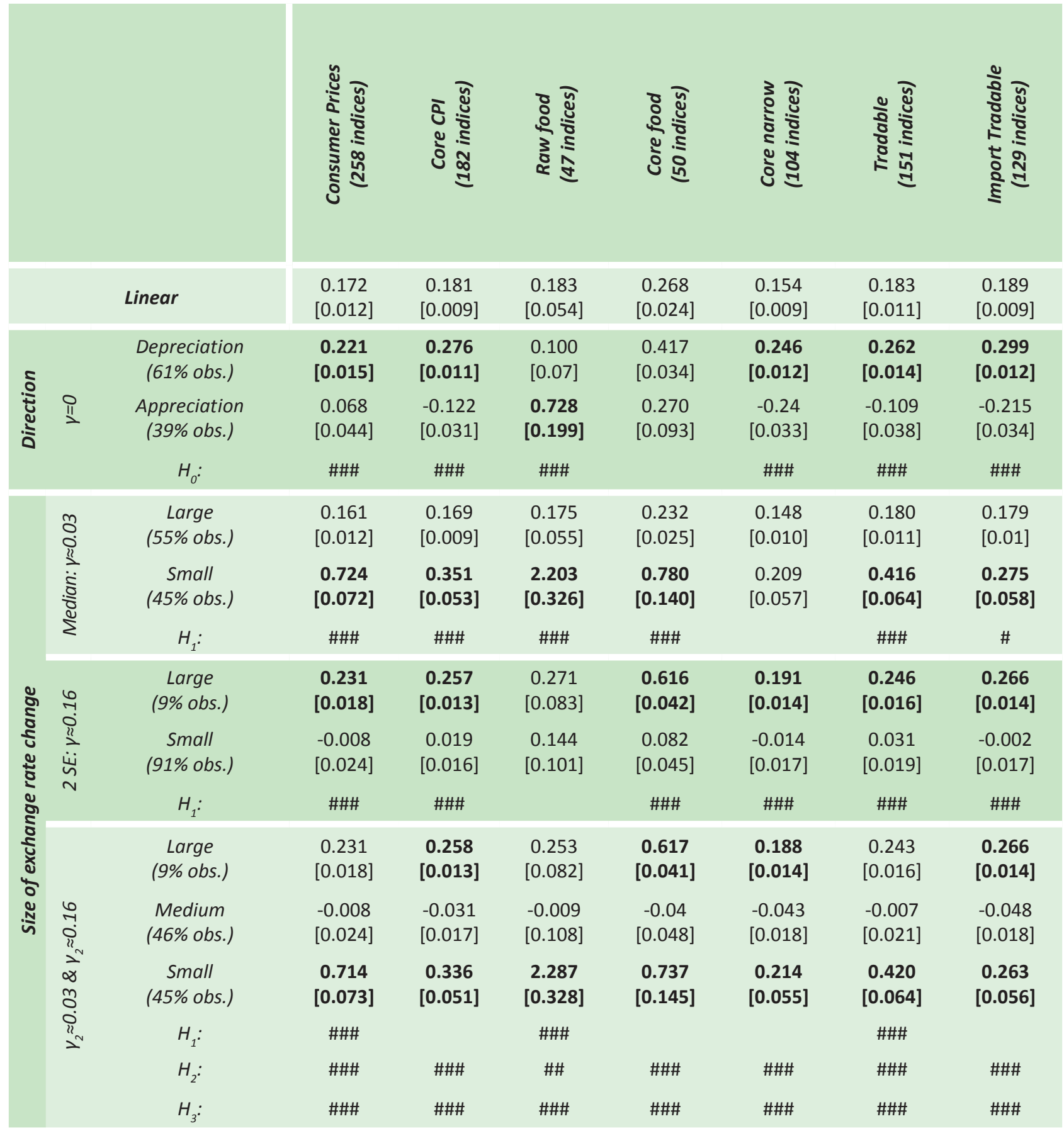

Notes: numbers are ERPT coefficients; numbers in [ ] are standard errors; $\gamma$-threshold value.

\#\#\#, \#\#, \# indicate 1, 5, 10 \% significance level to reject linearity hypotheses:

$\mathrm{H}_{0}$ : depreciation = appreciation

$\mathrm{H}_{1}$ : large $=$ small

$\mathrm{H}_{2}$ : large $=$ medium

$\mathrm{H}_{3}$ : medium $=$ small 
Figure 3. Price responsiveness to $1 \%$ NEER depreciation and appreciation

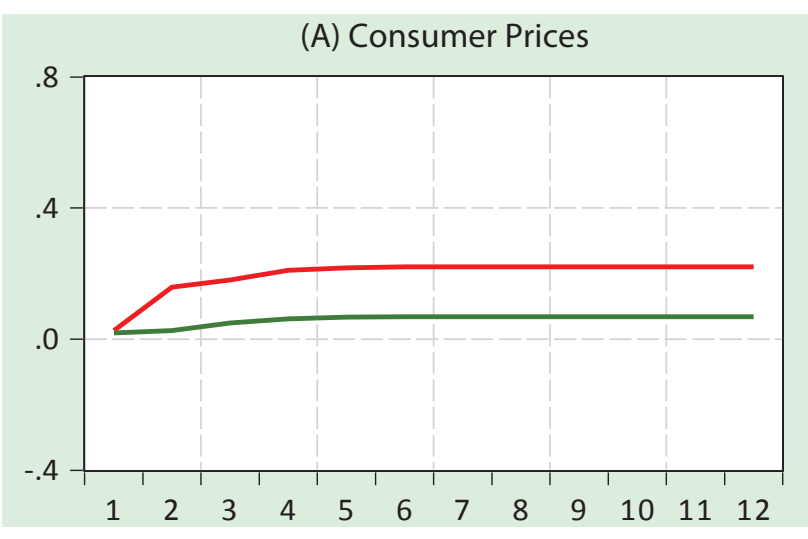

(B) Core Consumer Prices

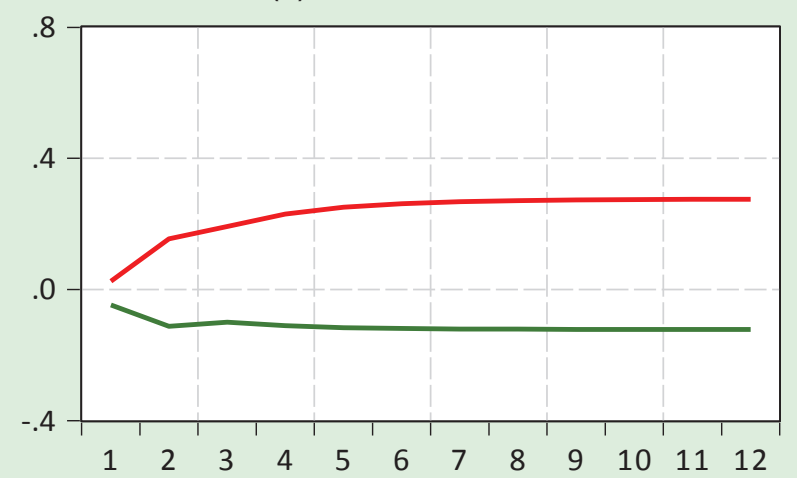

(C) Core Food Prices

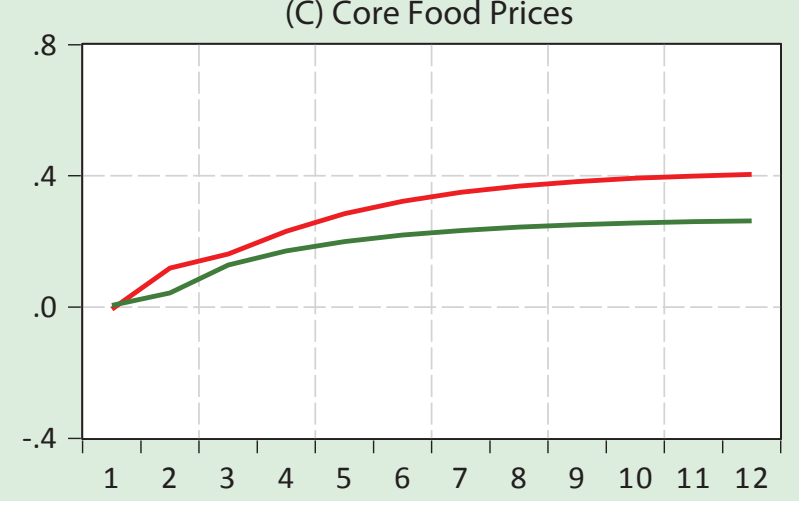

(E) Prices of Tradables

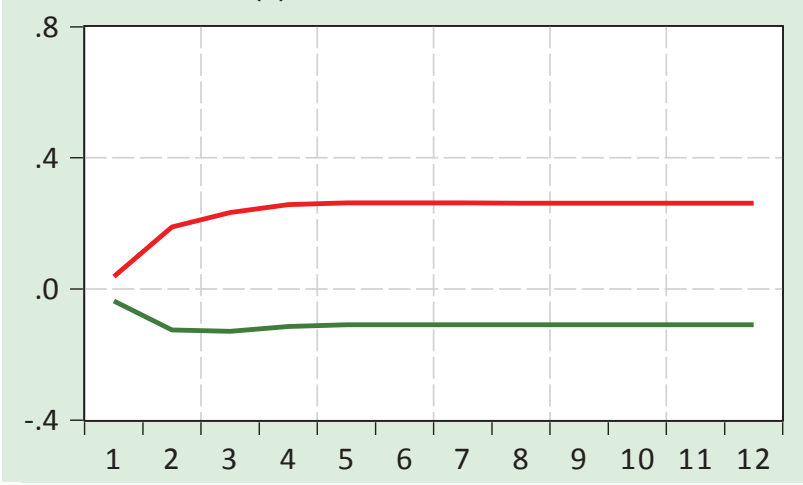

Depreciation $(\geq 0)$

Appreciation (<0)

(D) Raw Food Prices

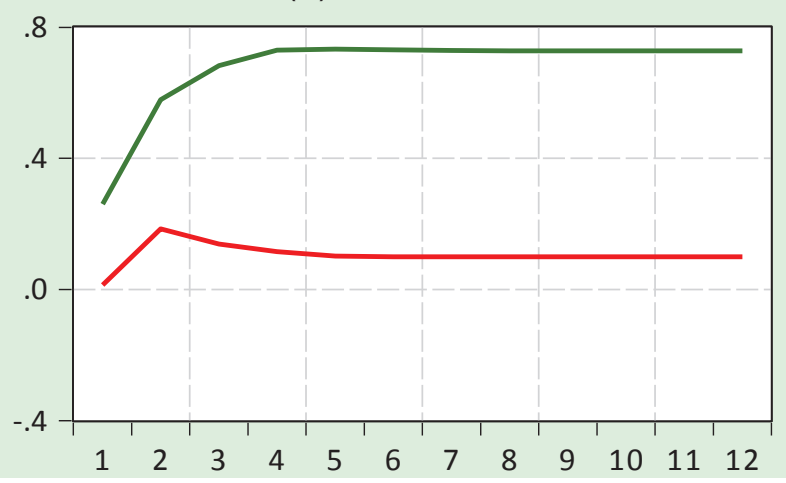

(D) Core Narrow Prices

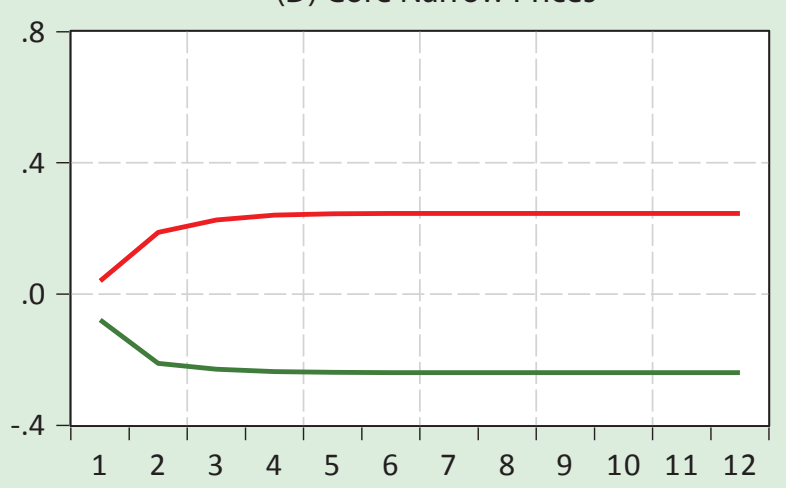

(F) Prices of Import Tradables

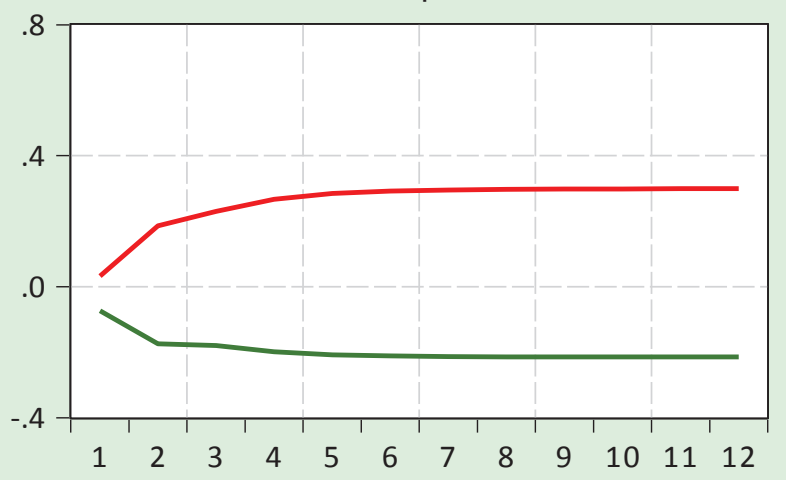

Note. Figures plot cumulative dynamic exchange rate pass-through coefficients for 12 month. 
Figure 4. Price responsiveness to large, medium, and small NEER changes

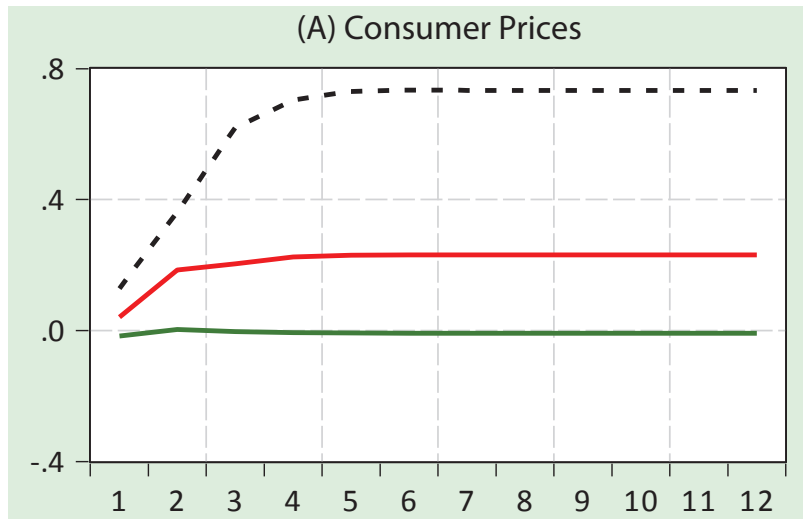

(B) Core Consumer Prices

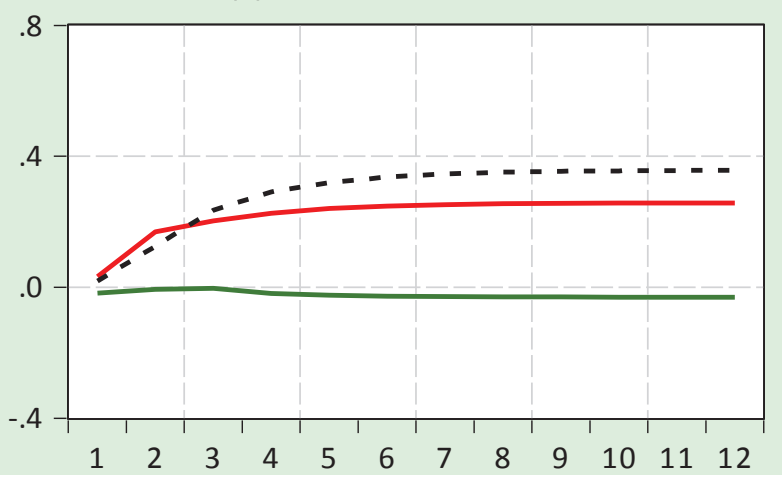

(D) Core Food Prices

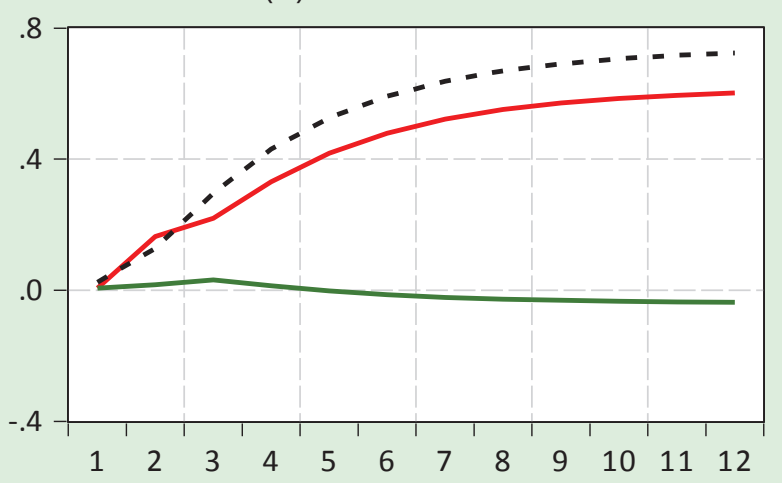

(F) Prices of Tradables

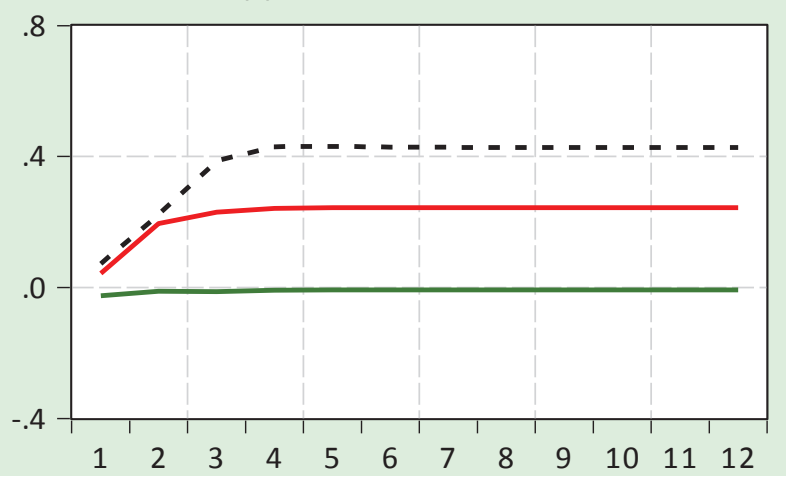

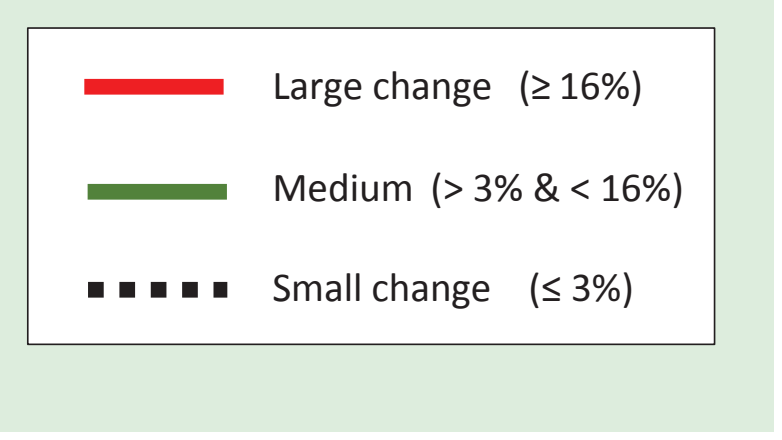

(C) Raw Food Prices

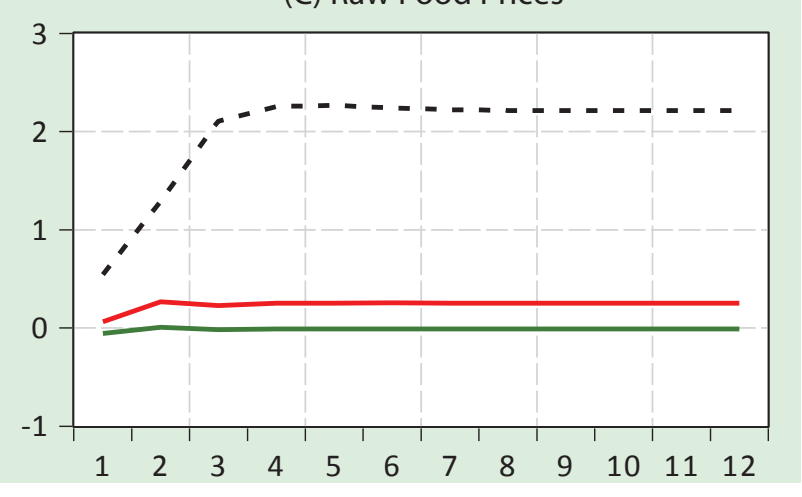

(E) Core Narrow Prices

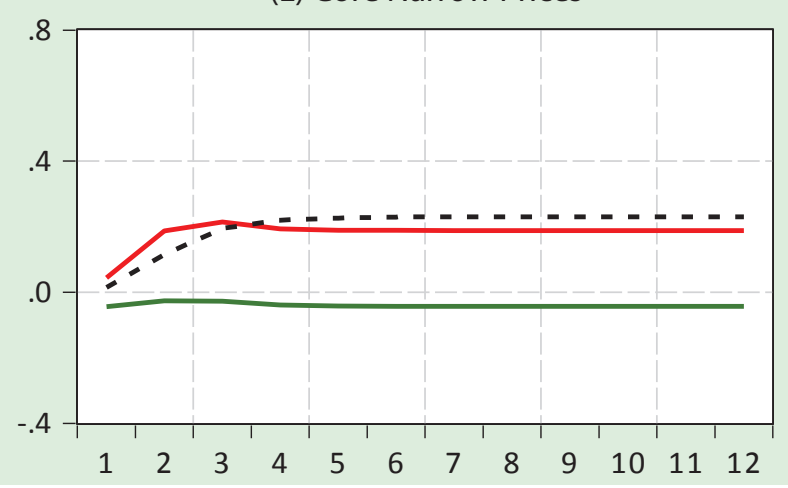

(G) Prices of Import Tradables

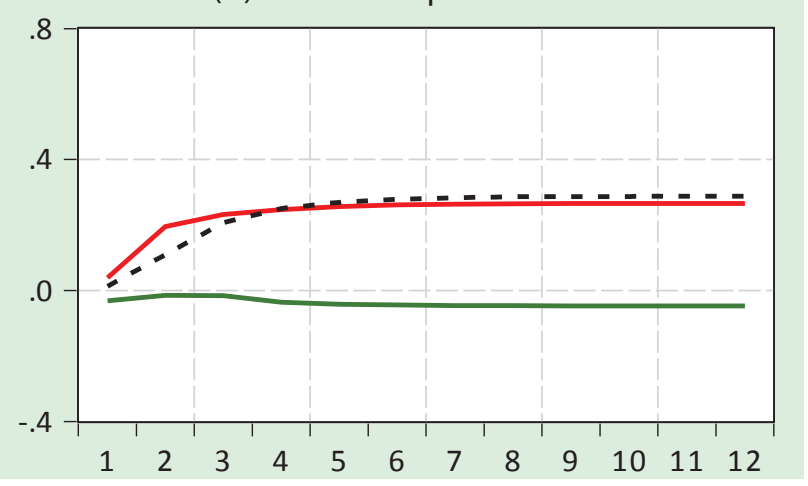

Note. Figures plot cumulative dynamic exchange rate pass-through coefficients for 12 month. 


\section{References}

- Bailliu J., Fujii E. (2004). Exchange Rate Pass-through and the Inflation Environment in Industrialized Countries: An Empirical Investigation. Working Paper, No. 2004-21, Bank of Canada.

- Beckmann E., Fidrmuc J. (2013). Exchange Rate Pass-Through in CIS Countries. Comparative Economic Studies, Vol. 55, No. 4, pp. 705-720. https://doi.org/10.1057/ces.2013.8

- Ben Cheikh N. (2013). Nonlinear Mechanism of the Exchange Rate Pass-Through: Does Business Cycle Matter? CREM UMR CNRS 6211, Working Paper, No. 2013-06, p. 21.

- Bussiere M. (2007). Exchange Rate Pass-Through to Trade Prices: The Role of Nonlinearities and Asymmetries. Working Paper, No. 822, ECB.

- Campa J.M., Goldberg L.S., González-Mínguez J.M. (2005). Exchange-Rate Pass-Through to Import Prices in The Euro Area. Working Paper, No. 11632, pp. 9-36, NBER. https://doi.org/10.3386/w11632

- Coibion O., Gorodnichenko Y. (2015). Inflation Expectations in Ukraine: a Long Path to Anchoring. Visnyk of the National Bank of Ukraine, No. 233, pp. 6-23. https://doi.org/10.26531/vnbu2015.233.006

- Delatte A.-L., López-Villavicencio A. (2012). Asymmetric Exchange Rate Pass-Through: Evidence from Major Countries. Journal of Macroeconomics, Vol. 34, pp. 833-844. https://doi.org/10.1016/j.jmacro.2012.03.003

- Faryna O. (2016). Exchange Rate Pass-Through and Cross-Country Spillovers: Evidence from Ukraine and Russia. BOFIT Discussion paper, No. 14, Bank of Finland, Institute for Economies in Transition.

- Goldberg P., Knetter M. (1997). Goods Prices and Exchange Rates: What Have We Learned? Journal of Economic Literature, No. 35, pp. 1243-1292.

- Koichi M. (2013). Asymmetric Effects of The Exchange Rate on Domestic Corporate Goods Prices. Japan and the World Economy, Vol. 25-26, pp. 80-89.

- Korhonen I., Wachtel P. (2006). A Note on Exchange Rate Pass-Through and Its Asymmetry in CIS Countries. Research in International Business and Finance, Vol. 20, No. 2, pp. 215-226. https://doi.org/10.1016/j.ribaf.2005.09.006

- Marston R.C. (1990). Pricing to Market in Japanese Manufacturing. Journal of International Economics, Vol. 29, No. 3-4, pp. 217-236. https://doi.org/10.1016/0022-1996(90)90031-G

- McCarthy J. (1999). Pass-Through of Exchange Rates and Import Prices to Domestic Inflation in Some Industrialized Economies. Working Papers, No. 79, p. 48, BIS.

- McCarthy J. (2007). Pass-Through of Exchange Rates and Import Prices to Domestic Inflation in Some Industrialized Economies. Eastern Economic Journal, Vol. 33, No. 4, pp. 511-537. https://doi.org/10.1057/eej.2007.38

- Nogueira Jr. R.P., Leon-Ledesma M. (2011). Does Exchange Rate Pass-Through Respond to Measures of Macroeconomic Instability? Journal of Applied Economics, Vol. 14, No. 1, pp. 167-180.

- Nogueira Jr.R.P., Leon-Ledesma M. (2008). Exchange Rate Pass-Through Into Inflation: The Role of Asymmetries and Nonlinearities. Studies in Economics, No. 0801, Department of Economics, University of Kent, p. 44.

- Novikova N., Volkov D. (2012). Modelling Core Inflation in Ukraine in 2003-2012. Economics Education and Research Consortium, Working paper, No. 12-12E.

- Pollard P.S., Coughlin C.C. (2004). Size Matters: Asymmetric Exchange Rate Pass-Through at The Industry Level. Working Paper No. 2003-029C, p. 38, Federal Reserve Bank of St. Louis.

- Shintani M., Terada-Hagiwara A., Yabu T. (2013). Exchange Rate Pass-Through and Inflation: A Nonlinear Time Series Analysis. Journal of International Money and Finance, Vol. 32, pp. 512-527. https://doi.org/10.1016/j.jimonfin.2012.05.024 